\title{
Glutamate Decarboxylase-Immunoreactive Neurons Are Preserved in Human Epileptic Hippocampus
}

\author{
Thomas L. Babb,, ${ }^{1,2}$ James K. Pretorius, ${ }^{2}$ William R. Kupfer, ${ }^{2}$ and Paul H. Crandall ${ }^{1-3}$ \\ Department of 'Neurology, ${ }^{2}$ Brain Research Institute, and the ${ }^{3}$ Division of Neurological Surgery, UCLA School of Medicine, \\ University of California, Los Angeles, California 90024
}

The present study was designed to determine whether inhibitory neurons in human epileptic hippocampus are reduced in number, which could reduce inhibition on principal cells and thereby be a basis for seizure susceptibility. We studied the distribution of GABA neurons and puncta by using glutamate decarboxylase (GAD) immunocytochemistry (ICC) together with Nissl stains. Using quantitative comparisons of GAD-immunoreactive (GAD-IR) neurons and puncta in human epileptic hippocampus and in the normal monkey hippocampus, we found that GAD-IR neurons and puncta are relatively unaffected by the hippocampal sclerosis typical of hippocampal epilepsy where $50-90 \%$ of principal (non-GAD-IR) cells are lost. GAD-IR neurons and puncta were not significantly decreased compared with normal monkey. In 6 patients, prior in vivo electrophysiology demonstrated that the anterior hippocampus generated all seizures. The anterior and posterior hippocampus were processed simultaneously, and the counts of hippocampal GAD-IR neurons were numerically greater in anterior than in the posterior hippocampus, where no seizures were initiated. These results indicate that GABA neurons are intact in sclerotic and epileptogenic hippocampus.

Computerized image analysis of puncta densities in fascia dentata, Ammon's horn, and subicular complex in epileptic hippocampi ( $n=7$ ) were not different from puncta densities in the same regions in normal monkey $(n=2)$. Hence, despite the significant loss of principal cells (50-90\% loss) GABA terminals (GAD-IR puncta) were normal, which suggests GABA hyperinnervation of the remnant pyramidal cells and/ or dendrites in human epileptic hippocampus. The apparent increase in puncta ranged from 2 (fascia dentata) to 3.3 (CA, times normal puncta densities. These findings would suggest increased inhibition and less excitability; however, those regions were epileptogenic. We suggest that GABA terminal sprouting or hyperinnervation of the few remnant projection cells may serve to synchronize their membrane potentials so that subsequent excitatory inputs will trigger a larger population of neurons for seizure onset in the hippocampus and propagation out to undamaged regions of subiculum and neocortex.

\footnotetext{
Received Oct. 11, 1988; revised Dec. 7, 1988; accepted Dec. 7, 1988.

We thank all the members of the Clinical Neurophysiology Project for their help in defining the physiology of the epileptogenic hippocampus used in this study. Special thanks is given to Maria Melendez for typing this manuscript. This work was supported by NIH Grant NS 02808 .

Correspondence should be addressed to Thomas L. Babb, Ph.D., at the above address.

Copyright (c) 1989 Society for Neuroscience $0270-6474 / 89 / 072562-13 \$ 02.00 / 0$
}

A reduction of inhibitory functions has been proposed as one cause of focal seizures in human epilepsy (Lloyd et al., 1985, 1986). Support for a chronic loss of GABAergic function in epileptogenic human cortex has been based on biochemical assays of tissue resected for relief of focal seizures (Lloyd et al., 1981, 1984). They have reported that in both epileptic and histologically damaged cortex, there are significant decreases in glutamate decarboxylase (GAD) activity (46\% of cases) or in GABA binding ( $44 \%$ of cases). However, the authors report that although they have carefully defined the origin of the seizures (epileptogenic zone or ZE), "for all cases studied to date the results are the same for $Z E$ and $Z L$ (lesion zone) from the same brains (e.g., for GAD activity $r=0.84 ; p<.01$ )" (Lloyd et al., 1981, p. 326).

This suggests that mere cell loss typical of epileptogenic foci may account for those cases where GAD activity $(46 \%)$ or GABA binding (44\%) was reduced. Other studies using similar biochemical assays on spiking and nonspiking neocortex have reported no significant differences in GABA, GAD, or GABA-T (van Gelder, 1981; Schmidt et al., 1984; Sherwin et al., 1984) or in low-affinity GABA-type benzodiazepine binding (Sherwin et al., 1986; Burnham et al., 1987). All these latter studies lack the anatomical control of what elements are labeled with homogenate binding of either crude or washed membranes, which did not yield different results (Burnham et al., 1987). Rather, the one consistent finding in that study was that the focal or spiking tissue had lower and more variable $B_{\max }$ (receptor numbers) than the remote nonspiking tissue. This again suggests that cell loss per se occurs in the spiking epileptic cortex, and anatomical controls for cell densities are essential for the interpretation of biochemical assays from epileptic tissue.

In order to provide a direct anatomic analysis of GABAergic neurons and terminals in expcrimcntal cpilcpsy, Ribak ct al. $(1979,1981,1986)$ have demonstrated a significant decrease in immunocytochemically-labeled GAD-positive neurons and puncta in and adjacent to an alumina-damaged epileptic focus in monkey motor cortex. In none of these reports, however, was there any measure of total cell loss in the necrotized or adjacent cortex. Hence, while it is clear that there is a loss of GABAergic neurons and terminals caused by the alumina damage, it is not known if that contributes to the epileptogenicity. The critical question remaining in these experimental anatomic studies of GABAergic innervation is whether the epileptic focus has a selective loss of GABA neurons or terminals or whether other neurotransmitter systems are equally decreased.

The present study was designed to test if GAD-IR neurons and puncta in human epileptic hippocampus were selectively 
decreased. It is well known that in human focal hippocampal epilepsy there is a significant loss of pyramidal neurons and dentate granule cells, based on routine Nissl stains and cell counts (Mouritzen-Dam, 1980; Babb et al., 1984a). The pattern and extent of this neuron loss is unique to epilepsy, and the site of seizure onset is localized to the greatest degree of hippocampal cell loss (Babb et al., 1984b). In the present study, the seizure foci for all the epileptic hippocampi resected (Crandall, 1987) were verified by chronic intrahippocampal electrographic and neuronal recordings of typical hippocampal seizures (Engel et al., 1983; Babbet al., 1987). The en bloc temporal lobe resection, including $3 \mathrm{~cm}$ of hippocampus, allowed us to microdissect the anterior and posterior hippocampus and subicular complex for cytology, GAD immunocytochemistry, and GAD-stained electron microscopy. The findings in this paper do not indicate a selective or significant loss of GAD-IR neurons or puncta in human epileptic hippocampus despite significant losses to nonGAD cells. GAD-IR neurons were numerically the same in anterior epileptic hippocampus as in the nonepileptic posterior hippocampus. This suggests that in human hippocampal epilepsy GABA function is relatively resistant to the pathogenic mechanisms responsible for sclerosis and focal seizures.

\section{Materials and Methods}

Physiology of human epileptic hippocampus. All 33 hippocampi used in this study had exclusively sclerosis typical of hippocampal epilepsy (Babb and Brown, 1987), and following hippocampal resection all patients had either no seizures or rare seizures, indicating that the removed hippocampus was indeed epileptogenic. There was no damage to any other part of these excised temporal lobes, not even to the subicular complex. Additionally, 27 of the 33 hippocampi were verified directly as epileptic because all electrographic seizures were recorded from intrahippocampal macroelectrodes (Engel et al., 1983) and/or microelectrodes (Babb et al., 1987). No depth electrodes were used in the other 6 cases, and their GAD-ICC results did not differ from the 27 .

Electrodes were chronically implanted for up to 4 weeks in order to record typical clinical seizures. Electrodes were placed bilaterally in basolateral amygdala, 3 levels of pes hippocampi (Ammon's horn: anterior, middle, and posterior), and 3 levels of gyrus hippocampi (parahippocampal gyrus: anterior, middle, and posterior). Electrodes were also placed in orbitofrontal gyrus and over neocortical regions approximately over the International 10-20 System (Jasper, 1958) with the exception of the occipital area. Hence, it was possible to localize the site(s) of seizure onset exclusively to the hippocampus; and no seizures originated outside the hippocampus.

The techniques for localizing exclusively unilateral seizure onsets to hippocampus have been described in detail (Engel et al., 1983), and in the 27 cases the seizures were classified as in a previous report (Babb et al., 1984b) as originating initially only from anterior hippocampus (anterior focal) or originating simultaneously from anterior, middle, and often posterior hippocampus (regional). In the previous report (Babb et al., 1984b), it was found that with anterior focal onsets the anterior pyramidal cell densities were significantly lower than posterior cell densities, which were not lower than normal controls. Ammon's horn cell densities were significantly lower than normal throughout anterior to posterior hippocampus with regional seizure onsets.

The most important comparison in this study was made with hippocampus having exclusively anterior focal seizure onsets. We compared the densities of GAD-IR cells in anterior and posterior hippocampi ( $n$ $=11$ ) because we had GAD-IR tissue from both anterior and posterior hippocampus, each within $10 \mathrm{~mm}$ of their respective electrode recording sites. Hence, the posterior GAD-IR cell densities served as a withinpatient control comparison for the anterior GAD-IR cell densities in testing the hypothesis that there is a relation between seizure onset site (e.g., anterior) and anterior GAD-IR cell density. Furthermore, adjacent sections within $60 \mu \mathrm{m}$ were Nissl-stained for total cell counts in fascia dentata, Ammon's horn, and subicular complex. It was important to test if all hippocampal cell densities, not just GAD-IR cells, had a pattern related to anterior focal versus regional seizure onsets, which was re- ported previously (Babb et al., 1984b). Those results were confirmed in the present study. Then, it was possible to contrast those cell densities to determine the percentage of anterior GAD-IR cells related to all anterior Ammon's horn cells for anterior focal seizure onsets. This provided an index of the gross anatomic integrity of GABAergic inhibition in human epileptic hippocampus. These same procedures were applied to hippocampi that had regional seizure onsets. Hence, this within-patient comparison provided the best direct test that GABA cell densities were not related to either the extent of hippocampal pathology or to its epileptogenicity.

Hippocampal fixation. The resected temporal lobes containing intact hippocampi were received on the average within $20 \mathrm{~min}$ from surgery. The hippocampi were immediately blocked with a razor blade into 3 to $4 \mathrm{~mm}$-thick sections and processed according to one of several different protocols. For routine light microscopy of GAD immunocytochemistry (ICC) and adjacent Nissl-stained sections, the blocks were immersion-fixed for $1-4 \mathrm{~d}$ in $4 \%$ paraformaldehyde $(\mathrm{pH} 7.2$ in $0.1 \mathrm{M}$ Millonig's buffer) and then cryoprotected in 15\% Millonig's buffered sucrose for $1-4 \mathrm{~d}$ before being cut into $30 \mu \mathrm{m}$ sections with a cryostat. To better visualize the GAD content of cell bodies and processes, 25 of the 33 blocks were initially immersed in Millonig's buffered saline ( $\mathrm{pH} 7.2$ ) for variable times from 1-2 hr prior to fixation. This procedure had been used by us routinely in rat and monkey, and those results are reported in detail in Babb et al. (1988a). For certain comparisons, the results from quantification of GAD-IR neurons in monkey hippocampi are included in this paper based on that previous report (Babb et al., 1988a).

Immunocytochemistry. Following sectioning, the tissue was collected into individual wells filled with $0.05 \mathrm{M}$ Tris- $\mathrm{HCl}$ buffered saline (TBS $\mathrm{pH}$ 7.6) and ICC staining for GAD was begun the same day. TBS was used throughout the protocol for all dilutions and rinses. Briefly, the sections were processed in the following sequence: $5 \mathrm{~min}$ in $3 \% \mathrm{H}_{2} \mathrm{O}_{2}$ $10 \%$ methanol; $5 \mathrm{~min}$ in filtered $0.25 \%$ Triton X-100; $60 \mathrm{~min}$ in a blocking solution of $10 \%$ normal rabbit sera and $0.1 \mathrm{M}$ DL-lysine monohydrochloride; overnight at room temperature in sheep anti-GAD (Oertel et al., 1981) diluted 1:2000 in $2 \%$ normal rabbit sera; $35 \mathrm{~min}$ in diluted biotinylated anti-sheep sera; and $60 \mathrm{~min}$ in a solution of avidinbiotinylated HRP (ABC. Kit, Vector I aboratories).

To visualize the GAD-ABC complex, the sections were reacted for $7-10 \mathrm{~min}$ in $0.05 \% 3,3^{\prime}$-diaminobenzidine tetrahydrochloride and $0.01 \%$ $\mathrm{H}_{2} \mathrm{O}_{2}$ in TBS. The reaction was halted by washing the sections in several changes of cold TBS. The sections were then mounted on chromiumalum gelatin-coated slides, air-dried for $4 \mathrm{hr}$, dipped for $35 \mathrm{sec}$ in $0.1 \%$ $\mathrm{OsO}_{4}$ in $0.1 \mathrm{M}$ phosphate buffer (pH 7.2), then dehydrated, and coverslipped.

As the test for the specificity of the primary GAD antisera, several sections were incubated in preimmunized normal sheep sera, diluted 1:1800 in place of the primary GAD antisera. Analysis of these sections revealed no immunocytochemical labeling except over areas of surgical remnants of unwashed red blood cells which were not adequately removed during immersion. Such cells are known to exhibit endogeneous peroxidase activity

Quantification of $G A D-I R$ and principal cells. In order to quantify the relative percentages of GAD-IR neurons to all Nissl-stained (hematoxylin and eosin, $H$ and $E$ ) neurons in stratum granulosum, stratum pyramidale, and the subicular complex, a grid sampling procedure was used (Babb et al., 1984a). First, the Nissl-stained section was oriented over the field so that the eyepiece grid covered the appropriate stratum for counting. After counting all the Nissl-stained cells, the adjacent GAD-IR tissue slide was similarly positioned by landmarks such as blood vessels or tissue cuts. Hence, the GAD-IR cell counts were within $60 \mu \mathrm{ms}$ of the Nissl cell counts, permitting an accurate estimate of the proportion of total cells that were GABAergic for each region counted. The average areas sampled were $13,520 \mu \mathrm{m}^{2}$ for stratum granulosum and $54,080 \mu \mathrm{m}^{2}$ for stratum pyramidale and subicular complex. The following regions were counted for both Nissl-stained and GAD-IR neurons: fascia dentata upper $\left(\mathrm{FD}_{u}\right)$ and lower $\left(F D_{1}\right), \mathrm{CA}_{4}, \mathrm{CA}_{3}, \mathrm{CA}_{2}$, $\mathrm{CA}_{1}$, prosubiculum (PRO), subiculum (SUB), and presubiculum (PRE). $\Lambda$ ccording to our previously published cytologic categories for epileptic hippocampus, (Babb et al., 1984a), the regions used to identify average Ammon's horn cell counts include $\mathrm{CA}_{4}, \mathrm{CA}_{3}, \mathrm{CA}_{2}, \mathrm{CA}_{1}$, and PRO.

Quantification of $G A D-I R$ neurons in Ammon's horn layers. In order to quantify the relative percentages of GAD-IR neurons in different cytologic regions and all strata of the normal monkey (Babb et al., 1988a) and epileptic human hippocampus, quantitative planimetry of GAD- 
IR cells and of Nissl-stained cells was used to calculate the percentage of all cells ( $\mathrm{H}$ and $\mathrm{E}$ stained) that were GABAergic (GAD-IR) in adjacent sections. Two sections each from 2 adult monkeys and 1 section each from 2 human epileptics were used in this counting study. Two dimensional counts (cells $/ \mathrm{mm}^{2}$ ) were converted to volumetric cell densities (cells $/ \mathrm{mm}^{3}$ ) using the Abercrombie correction (Abercrombie, 1946). All counts were made at 250 times magnification using 1 of 2 methods: (1) for Nissl-stained pyramidal and granule cell layers, cell densities were calculated using an eyepiece grid sampling procedure (for details, see Babb et al., 1984a); (2) for all other layers in both GAD-IR and $H$ and E-stained sections, all identifiable cells were counted within the specified layer of each subfield. Because the area varied for each layer and subfield, a computer-based planimetry system (Videoplan, Zeiss Inc.) was used for precise measurement of the area from which the cell counts were made. This procedure and the results for the monkey hippocampal formation have been given in detail (Babb et al., 1988a). Densities of GAD-IR cells were divided by the Nissl-stained cell densities in each region to give a percentage of GAD-IR cells for a given Ammon's horn region, which ranged from $4 \%$ (monkey stratum pyramidale) to $100 \%$ (e.g., human epileptic radiatum).

Computerized GAD-IR puncta counts. In order to define the density and distribution patterns of GABAergic terminals (GAD puncta in different subregions of the fascia dentata, hippocampus, and subicular complex), one GAD-stained $30 \mu \mathrm{m}$ section each from similar regions of the ventral hippocampus in 2 monkeys was studied by quantitative densitometry (IBAS, Zeiss Inc.), as previously described in detail (Babb et al., 1988a). Seven anterior human epileptic hippocampi were similarly imaged for puncta densities in all regions from fascia dentata, hippocampus, and subicular complex. The human epileptic puncta average areas ranged from $0.94 \mu \mathrm{m}^{2}$ in PRO to $1.15 \mu \mathrm{m}^{2}$ in $\mathrm{FD}_{u}$, and none of the average puncta areas differed from the average puncta areas in normal monkey, which ranged from $0.79 \mu \mathrm{m}^{2}$ in $\mathrm{CA}_{4}$ to $1.05 \mu \mathrm{m}^{2}$ in $\mathrm{CA}_{2}$.

Control comparisons. In order to test whether GAD-IR neurons and puncta were altered in human epileptic hippocampal formation, 3 control comparisons were used. First, as previously mentioned, GAD-IR densities were compared in human anterior epileptic hippocampus to the posterior noncpileptic hippocampus in the same patients. This provided the best possible comparison between seizure onset site and GABA neurons because the tissues were processed simultaneously to avoid ICC staining variability and there was no cross-species comparison (see Fig. 8). It should be emphasized that this control comparison is the same strategy used in animal studies of GABA and seizure sites (e.g., Ribak et al., 1979, 1981, 1986). The second comparison was not a withinpatient comparison; however, the comparison between anterior/middle epileptic hippocampus to the nonepileptic posterior hippocampus had cell counts from 27 patients. This provided enough statistical power to overcome random staining variability (see Fig. 7). The third comparison used GAD and Nissl stain counts from homologous hippocampal sites in normal monkey. Although it may be suggested that there are cytologic differences between monkey and man, we have found that both GADIR and principal cell densities are not significantly different between the monkey subiculum and the undamaged subiculum of the human epileptic (see Figs. 2, 3). Furthermore, we have previously shown that in stratum pyramidale the GAD-IR cell densities are not different (3-4\% of all cells) between rat and monkey (Babb et al., 1988a). The GADIR neuron densities are similar between anterior and posterior ventral hippocampus of the monkey. Hence, we feel that the normal primate hippocampus provides a reasonable comparison to normal human hippocampal subfields; although good "normal" post-mortem hippocampus must be studied to validate these monkey comparisons. At present, most post-mortem tissue, especially hippocampus, is either unavailable or unacceptable for good ICC studies.

\section{Results}

$G A D-I R$ and principal neurons in human epileptic hippocampus

Figure $1 A$ shows a representative example of hippocampal sclerosis in human hippocampal epilepsy. This hippocampus has a typical pattern of cell loss (bluish stain) and reactive astrocytes (pink stain) from the fascia dentata (FD) throughout Ammon's horn (e.g., $\mathrm{CA}_{3}, \mathrm{CA}_{1}$ ) to the SUB. The point of relatively normal cell densities in the SUB is shown clearly by the end of the zone of staining of astrocytes (arrow) in both the cell body layer and the dendritic fields. To the left of the arrow normal cell densities and dendrites are evident. Too the right of the SUB, there is increased cellularity corresponding to astrocytic gliosis in the $\mathrm{PRO}$, but in $\mathrm{CA}_{1}$ (bluish stain) there are so few neurons and glia that the stain is faint. As is typical of many human epileptic hippocampi, there are some pyramidal neurons spared in $\mathrm{CA}_{2}$ (box), which can be seen in more detail in $C$ (arrows). To the right of $\mathrm{CA}_{2}$ in the box $(C), \mathrm{CA}_{1}$ had only $6 \%$ of normal cell densities (i.e., a $94 \%$ cell loss) compared to the $82 \%$ cell loss in $\mathrm{CA}_{2}$.

In Figure $1 B$ the G $\Lambda$ D-IR adjacent section (within $30 \mu \mathrm{m}$ ) shows a pattern found in all the human epileptic hippocampi. At this low-power magnification, remnant granule cells (FD) and pyramidal cells $\left(\mathrm{CA}_{3}, \mathrm{SUB}\right)$ appear clear because they do not contain GAD. However, the shapes are evident because GAD-IR puncta surround the cell bodies (e.g., CA, neurons in D). Most important, despite the severe cell losses of all principal cells, GAD-IR neurons can be seen in all fields, although not clearly at this magnification. The important pattern in Figure $1 B$ is that the regions of principal cell sparing (FD lower blade, $\mathrm{CA}_{3}, \mathrm{CA}_{2}, \mathrm{SUB}$ ) can be seen as GAD-IR puncta outlines, which suggests that at least a proportional number of GABAergic neurons and axons are retained in the sclerotic hippocampus as would be seen in normal hippocampus.

Figure $2, A, B$, are schematic drawings of human epileptic $(A)$ and normal monkey $(B)$ hippocampus with percentages of GADIR cells as a proportion of all $\mathbf{H}$ and E-stained cells. These percentages show clearly that in the human epileptic hippocampus GAD-IR neurons are spared compared with the principal cells of FD and all CA fields to the subiculum. For example, in CA GAD-IR neurons represent $79 \%$ of all cells in human epileptic $(A)$ but only $4 \%$ in normal monkey $(B)$ because $\mathrm{CA}_{1}$ pyramids are vulnerable to epileptic sclerosis, while nearby GADIR neurons are relatively spared. This pattern of a greater percentage of GAD-IR neurons in human epileptic hippocampus ends in the SUB where pyramidal cells and GAD-IR neuron densities are normal compared to monkeys (see Fig. 1, $A, C$ ). In the PRE, the difference between $5 \%$ (human epileptic) and $10 \%$ (normal monkey) is not significant. This demonstrates that the densities of GAD neurons in normal monkey hippocampus are probably comparable to human, which would justify the use of the monkey GAD-ICC as a "control."

In the other layers of the human epileptic hippocampus, GAD. IR densities $(A)$ are also greater than normal $(B)$. GAD-IR neurons are proportionately greater in epileptic $\mathrm{CA}_{3}$ stratum oriens (SO: 50 vs $15 \%$ ), stratum radiatum (SR: 58 vs $32 \%$ ), and lacunosum-moleculare (SLM: 100 vs $25 \%$ ). However, in a few fields the GAD-IR neurons were proportionately the same [e.g., the polymorph layer (PL) of FD or SR of $\mathrm{CA}_{1}$ ]. Hence, these data indicate that GAD-IR neurons are relatively spared in human sclerotic epileptic hippocampus.

Figure 3 is a plot of the percentage of GAD-IR cell loss (black squares at top) relative to control monkey for each principal cell layer in FD, Ammon's horn, and the subicular complex. In field $\mathrm{CA}_{3}$ stratum pyramidale ( $n=33$ epileptic hippocampi), there was a $30 \%$ average loss of GAD-IR neurons compared to $\mathrm{CA}_{3}$ in monkeys, but it was not statistically significant. There was no other significant difference, which indicated that the population of GAD-IR neurons in human epileptic hippocampus $(n=33)$ is almost normal when compared numerically with 

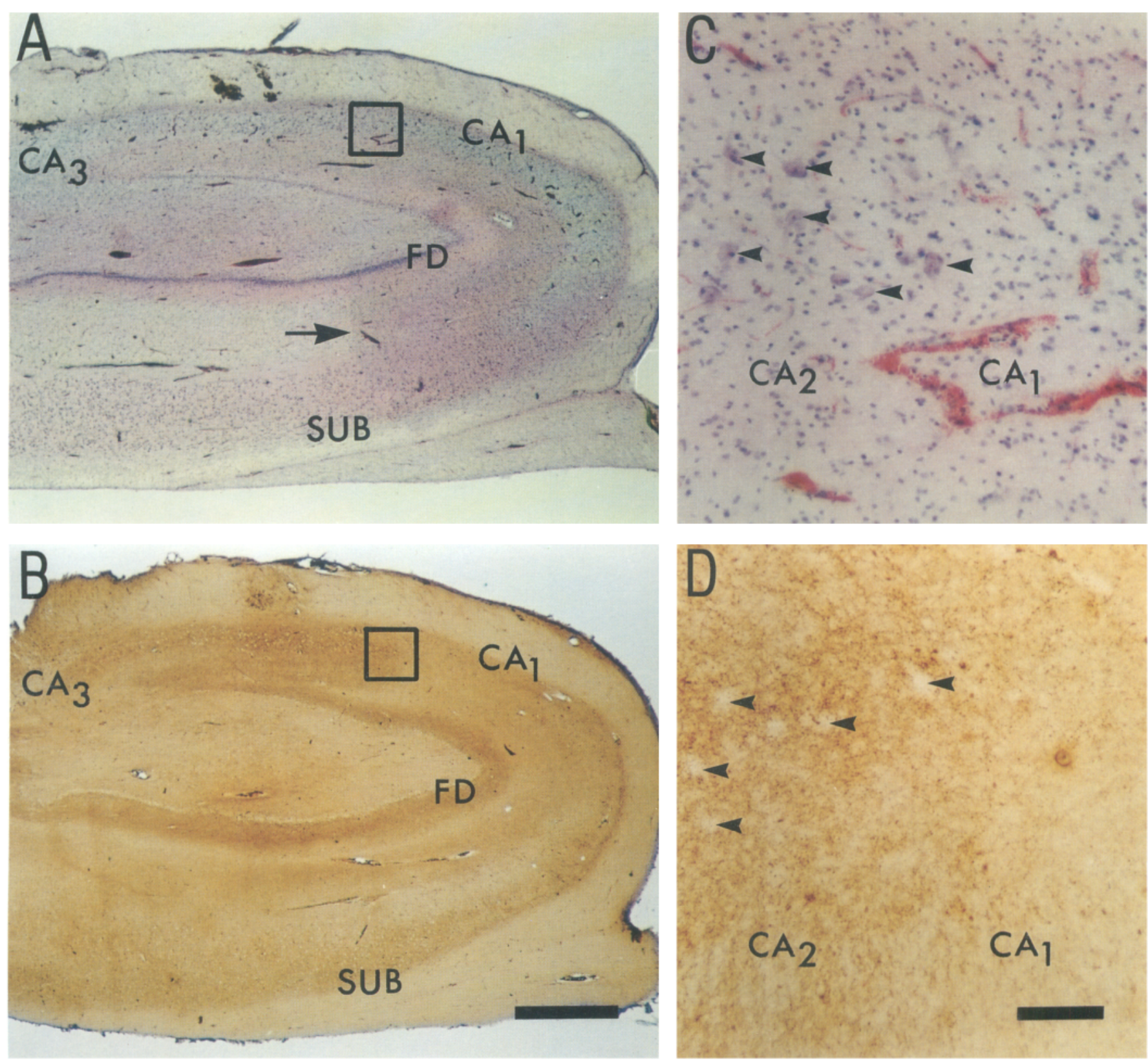

Figure 1. Color photomicrographs of human epileptic hippocampus stained adjacently with $\mathrm{H}$ and $\mathrm{E}(A)$ or GAD-ICC $(B)$. In $A$, there is a cell loss pattern typical of hippocampal sclerosis in which neurons are decreased from FD to the SUB (arrow). There is neuronal loss throughout stratum pyramidale,with an increase in the number of astrocytes. Note that in SUB (arrow) there is a sharp recovery of neurons and dendrites. There is relative sparing of $\mathrm{CA}_{2}$ neurons (box), which can be seen in more detail (C, arrowheads), but the adjacent $\mathrm{CA}_{1}$ has fewer neurons. The red deposits are residual blood remaining after immersion fixation. In $B$, within $60 \mu \mathrm{m}$, is the GAD-IR section that shows clear non-GAD granule cells in FD and pyramidal cells in CA fields and subicular complex (SUB). In $D$ (boxed area of $B$ ), the remnant $C_{2}$ pyramidal cells appear clear (arrowheads) and surrounded by GAD-IR puncta. Scale bars: $A$ and $B, 1 \mathrm{~mm} ; C$ and $D, 100 \mu \mathrm{m}$.

normal primate GAD-IR neurons. By contrast, Figure 3 also plots the percentage of cell loss (open squares at bottom) for all $\mathrm{H}$ and E-stained cells in the epileptic $(n=33)$ relative to normal human controls $(n=4)$. A similar plot was obtained when comparing the epileptic to the $\mathrm{H}$ and $\mathrm{E}$ counts in monkeys. There are statistically significant decreases in all regions except for SUB and PRE (see Fig. 1 $A$ ). These 2 plots were based on all 33 epileptic hippocampi that met the criteria of exhibiting typical sclerosis and seizure relief after excision. These plots confirm that principal cells, not GAD-IR cells, are preferentially and significantly damaged in human hippocampal epilepsy.
Figures 4-6 are photomicrographs assembled to illustrate typical features of GAD-IR neurons in $\mathrm{FD}, \mathrm{CA}_{3}$, and $\mathrm{CA}_{1}$ respectively. Figure $4 B$ shows granule cells that were decreased by $72 \%$ from normal. However, GAD-IR neurons were not reduced from normal. In the stratum moleculare (Fig. 4A) there is a typical GAD-IR (GAD+) neuron with diverse dendrites (arrowheads) spanning over $200 \mu \mathrm{m}$. In the polymorph layer (Fig. $4 C$ ) beneath SG there is a typical basket cell with multiple dendrites (arrowheads), a darkly stained cytoplasm, and a clear nucleus. These are apparently normal cells because GAD is contained in the cytoplasm, not in the nucleus. 

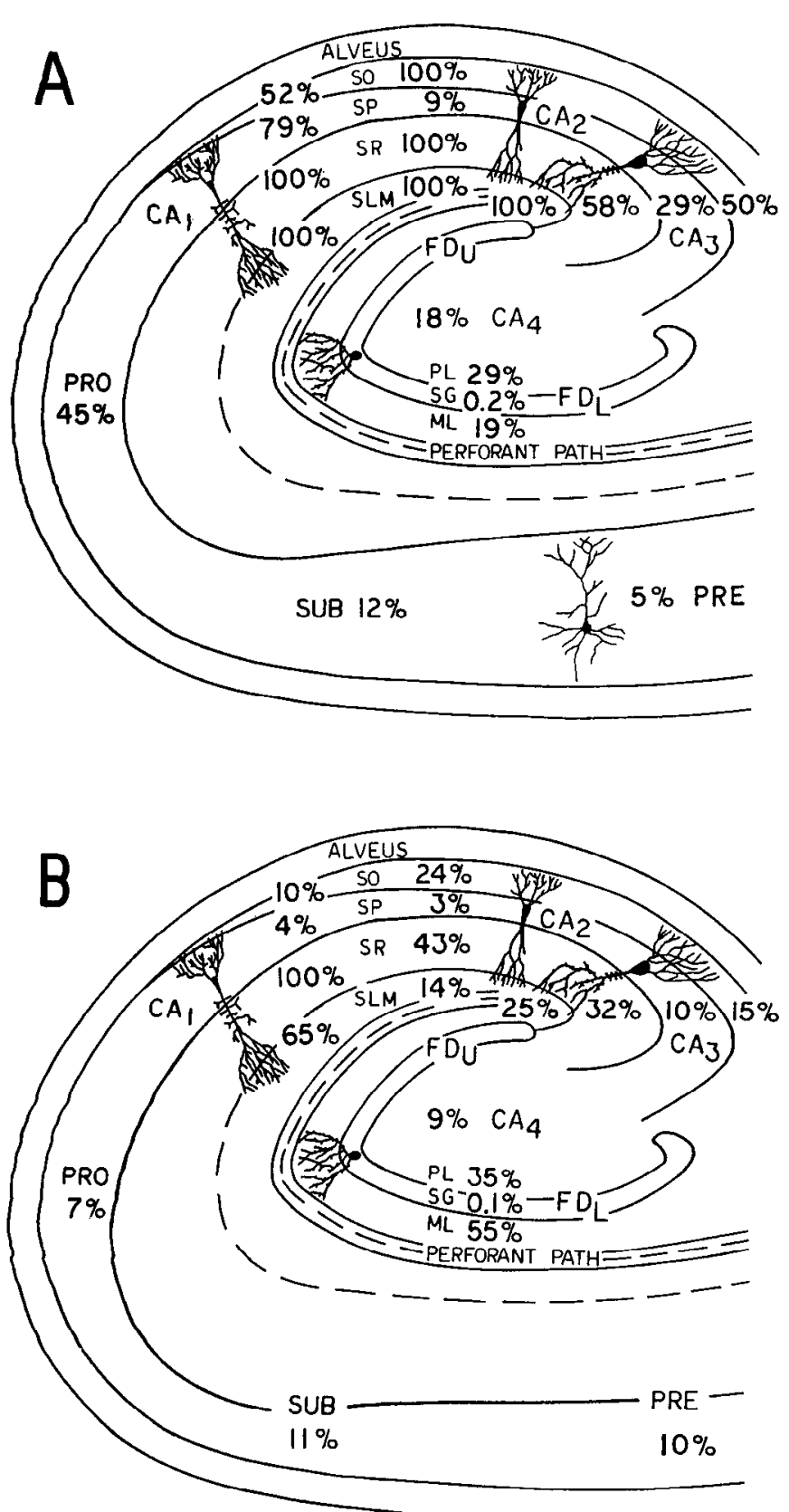

Figure 2. Schematic drawings of hippocampal formation from human epileptic $(A)$ and normal monkey $(B)$ to contrast the relative percentages of GAD-IR neurons in each region counted. Note that in most regions except the subiculum, the percentage of all $H$ and $E$ cells that are GADIR is much higher for human epileptic than monkey hippocampus. Schematic drawings of granule cells and pyramidal cells with their dendritic patterns are included, based on camera lucida drawings from normal Golgi-stained primate hippocampus.

Figure $5 A$ shows 2 pyramidal cells $(\mathrm{P})$ in a field of $\mathrm{CA}_{3}$ that had $74 \%$ cell loss but only a $30 \%$ loss of GAD-IR neurons. Typically, in the absence of pyramids, astrocytes (a) occupy space and GAD-IR neurons are also present in the stratum pyramidale. In the subjacent stratum radiatum (Fig. $5 B$ ) there is a typical basket cell $(\mathrm{GAD}+)$ with spreading dendrites (arrowheads), darkly stained cytoplasm, and a clear nucleus.

Figure $6 B$ shows the $H$ and $E$ stain of a pyramidal cell $(P)$ in the $\mathrm{CA}_{1}$ field in which pyramids were reduced by $84 \%$, astrocytes

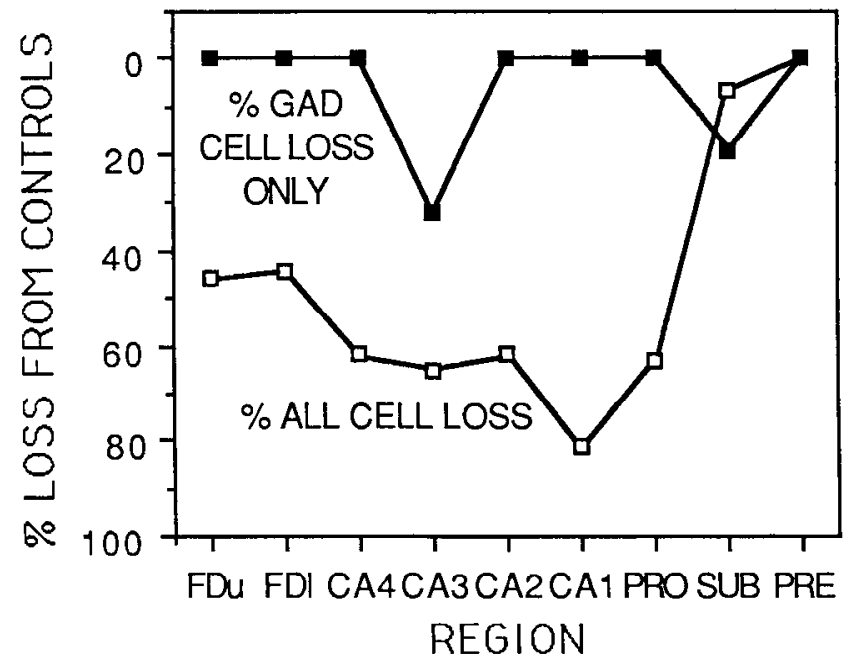

Figure 3. Plot of the percentage of GAD-IR cell loss (black squares) in human epileptic hippocampus exhibiting typical hippocampal sclerosis $(n=33)$ compared with normal monkey $(n=2)$ GAD-IR neurons. Note that although there is a $30 \%$ decrease in $\mathrm{CA}_{3}$, neither that or any other region had a statistically significant GAD-IR neuron loss. By contrast, all hippocampal fields have significant total cell ( $\mathrm{H}$ and $\mathrm{E}$ counts) loss in human epileptic $(n=33)$ compared with human autopsy controls ( $n-4$, open squares), except for subiculum and presubiculum.

(a) were increased and the GAD-IR neurons were reduced by only $30 \%$. In the stratum oriens (Fig. $6 A$ ) there is a bipolar type GAD + cell typically found in that layer. The large dendrites (arrowheads) span the oriens and often enter either the alveus or stratum pyramidale. Small axons from these cells run parallel to the dendrites to enter stratum pyramidale. In the stratum radiatum (Fig. $6 \mathrm{C}$ ) there is a basket cell typical of that layer for all regions of Ammon's horn (e.g., $\mathrm{CA}_{3}$, Fig. $5 B$ ). There are widespread dendrites (arrowheads), dark cytoplasm, and a clear nucleus.

\section{GAD-IR neurons: anterior to posterior distribution}

Figure 7 shows 3 histograms comparing information from anterior, middle, and posterior epileptic hippocampus taken from 27 patients who met 3 criteria for localization of the seizures to that hippocampus: (1) all seizures originating cxclusively from intrahippocampal electrodes, (2) seizure relief after hippocampal excision, and (3) typical hippocampal sclerosis. Although there is no statistically significant difference between any comparison, it is worth noting that despite the greater overall cell loss $(\mathrm{H}$ and $E$ counts, Fig. $7 B$ ) in ANT and MID hippocampus, which are significantly more epileptogenic, there are more, not fewer, GAD-IR neurons (Fig. 7A, ANT, MID) than in the posterior hippocampus (Fig. $7 A$, POST). In other words, there are fewer total cells anteriorly (Fig. $7 B$ ) but more GAD-IR cells anteriorly (Fig. 7A), which indicates again that GABAergic cells are probably resistant to epileptic hippocampal sclerosis. Figure $7 C$ is a histogram that illustrates the averaged percentage of Ammon's horn neurons in stratum pyramidale that are GAD-IR relative to all $\mathrm{H}$ and $\mathrm{E}$ cells. The percentages of GAD-IR neurons are $51 \%$ (ANT), $61 \%$ (MID), and 35\% (POST).

\section{GAD-IR neurons: anterior focal versus regional seizure onsets}

In 11 cases, both anterior and posterior hippocampi were processed simultaneously after resection. This provided a within- 

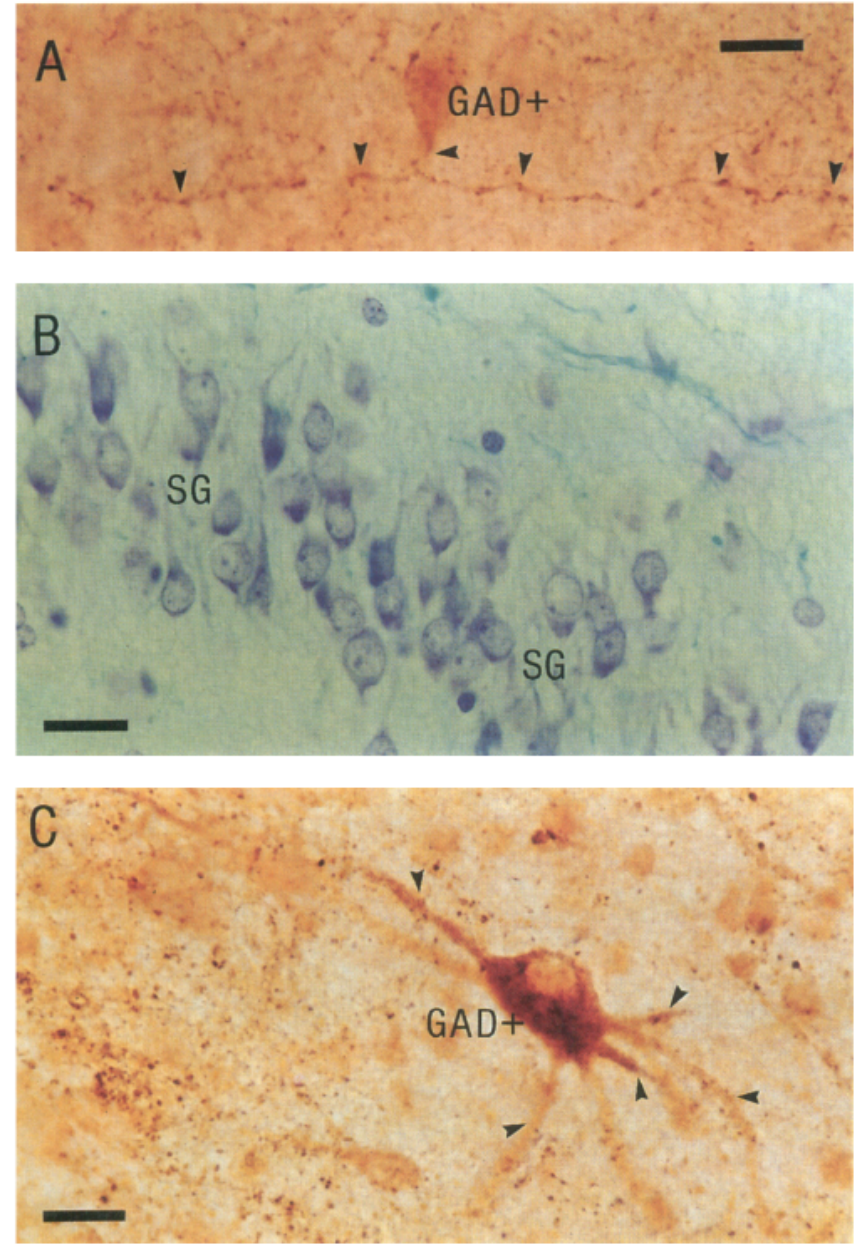

Figure 4. Color photomicrographs of GAD-IR neurons $(\mathrm{GAD}+)$ and their dendritic process (arrowheads) in stratum moleculare $(A)$ and polymorph layer $(C)$ with a typically sclerotic epileptic stratum granulosum (B: SG). Granule cells were decreased by $72 \%$, while the GAD-IR cells were not decreased from controls. The darker background in $A$ compared with $C$ was due to extra photographic development to reveal the extensive dendrites (arrowheads) spanning the area in $A$. $C$ represents a typical polymorph basket cell. Scale bars, $20 \mu \mathrm{m}$.

patient comparison between the numbers of GAD-IR neurons. These counts were then compared with the hippocampal region of seizure onsets. The GAD-IR and $\mathrm{H}$ and $\mathrm{E}$ cell counts were completed without knowledge of the hippocampal seizure site(s). Anterior focal $(n=6)$ seizures were compared with regional onset $(n=5)$ seizures (for criteria and details, see Babb et al., 1984b). Figure 8 shows 3 histograms arranged similarly to Figure 7 for comparing cell counts $(A, B)$ and the percent GADIR cells $(C)$. In Figure 8, however, the counts are based on the site(s) of seizure onsets, i.e., anterior focal or regional (nonfocal). As expected, in Figure $8 B$ the average Ammon's horn $\mathrm{H}$ and $\mathrm{E}$ counts were significantly decreased in both anterior or posterior hippocampus for either anterior focal or regional seizure onsets because both seizure types had significant sclerosis in Ammon's horn similar to that plotted in Figure 3. On comparing anterior to posterior hippocampus between seizure onset types, there were fewer cells anterior than posterior for anterior focal onset seizures. Although not statistically significant here, the pattern was similar to that previously reported (Babb et al., 1984b). For regional onset seizures, average Ammon's horn cell loss was
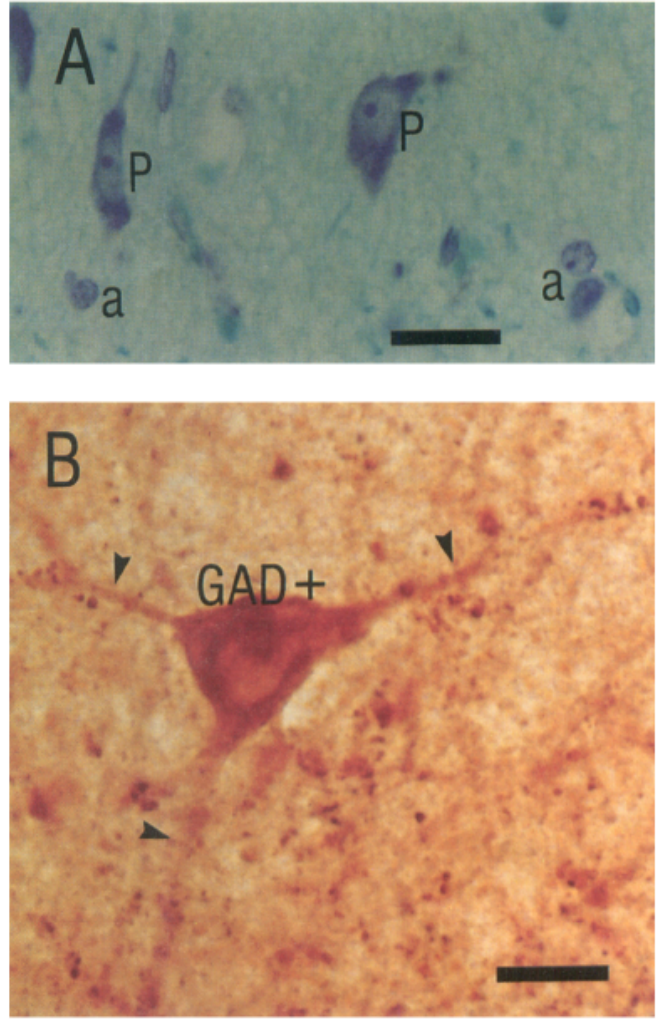

Figure 5. Color photomicrographs of a GAD + neuron in stratum radiatum of epileptic $\mathrm{CA}_{3}$ with nearby pyramidal neurons $(P)$ decreased by $74 \%$ and replaced by abundant astrocytes $(a)$. GAD-IR neurons in this same area were decreased by only $30 \%$. Note the typical basket cell shape $(B)$ of the GAD+ neuron with numerous dendrites (arrowheads). Scale bars, $20 \mu \mathrm{m}$.
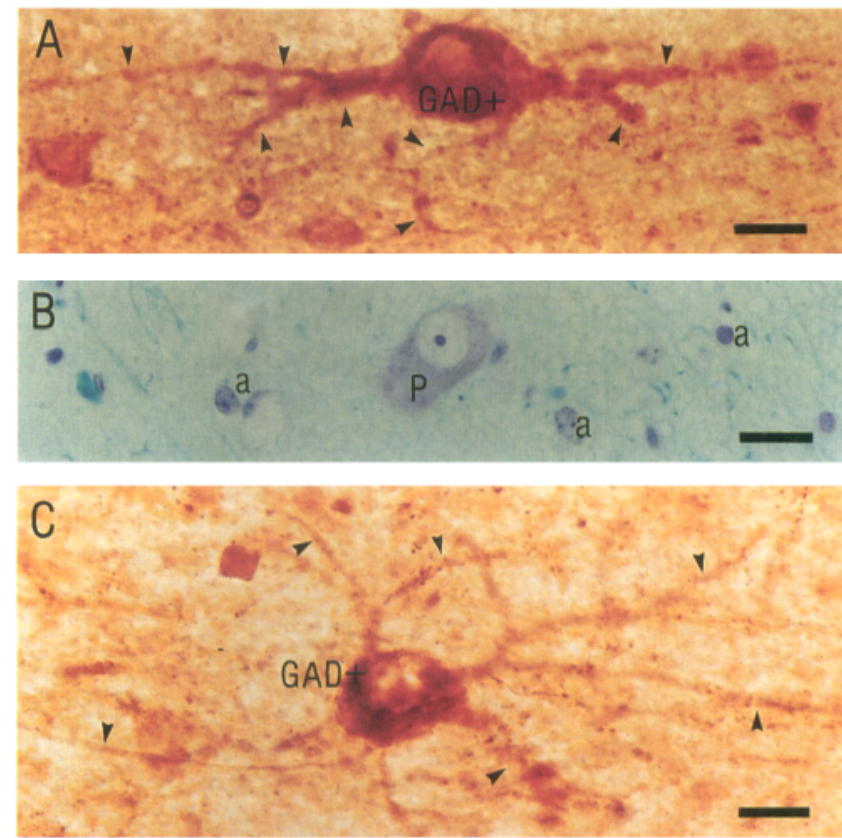

Figure 6. Color photomicrographs of epileptic $\mathrm{CA}_{1} \mathrm{GAD}+$ neurons in stratum oriens ( $A$ : bipolar type) and stratum radiatum $(C$ : basket type), each having abundant dendritic plexuses (arrowheads). In $B$, the $\mathrm{CA}_{1}$ pyramidal neurons $(P)$ were decreased by $84 \%$ and replaced by astrocytes $(a)$. GAD-IR neurons were reduced by $30 \%$. Scale bars, 20 $\mu \mathrm{m}$. 
Table 1. Average number of GAD-IR neurons (cells $/ \mathrm{mm}^{3}$ ) counted in anterior and posterior hippocampus of 6 patients with anterior focal seizure onsets.

\begin{tabular}{lllc} 
Patient & Anterior & Posterior & A $\div$ P \% \\
\hline 1 & 4488 & 2244 & 200 \\
2 & 2640 & 2970 & 89 \\
3 & 3630 & 3960 & 92 \\
4 & 4752 & 4224 & 113 \\
5 & 2376 & 1848 & 129 \\
6 & 5115 & 2640 & 194 \\
$n=6$ & 3834 & 2981 & 129
\end{tabular}

The percent difference $(\%)$ is calculated as Anterior $\div$ Posterior.

greater when compared with anterior focal onsets in both anterior and posterior hippocampus. Again, though not statistically significant, these results indicate a greater sclerosis along the anterior to posterior extent of the hippocampus with regional onset seizures.

Figure $8 A$ shows the GAD-IR cell counts from within $60 \mu \mathrm{m}$ of the $\mathrm{H}$ and $\mathrm{E}$ counts (Fig. $8 B$ ). For anterior focal seizure onsets, GAD-IR neurons in anterior hippocampus are actually more numerous than in posterior hippocampus, where there is less sclerosis (Fig. 8B) and no focal epileptogenesis. In other words, anterior hippocampus is epileptic but has more GABAergic neurons. With regional onsets, there was a similar pattern, but less of a numerical difference between GAD-IR neurons in anterior and posterior hippocampus than was found with anterior focal onsets. None of these comparisons was statistically significant; hence GAD-IR neuron densities are not preferentially related to site(s) of epileptogenesis (Fig. $8 A$ ) or to extent of hippocampal sclerosis (Fig. $8 B$ ). Rather, when we calculated a histogram of the percentage of GAD-IR neurons (Fig. $8 A$ ) as a proportion of all $\mathrm{H}$ and $\mathrm{E}$ neurons (Fig. 8B), the more epileptogenic and sclerotic anterior hippocampus had the greater percentage of neurons (Fig. 8C, stippled bars for ANT FOCAL and REGIONAL). For example, with anterior focal seizures, 53\% of Ammon's horn cells in stratum pyramidale were GAD-IR in anterior hippocampus, while only $34 \%$ in the posterior hippocampus were GAD-IR.

Finally, Table 1 shows the actual average Ammon's horn GAD-IR counts in anterior versus posterior hippocampus for the 6 patients with anterior focal seizure onsets. Only 2 of 6 had fewer GAD-IR cells anteriorly, and the differences were only 8 and $11 \%$ less than posteriorly. On average, there were $29 \%$ more GAD-IR neurons anterior than posterior when that anterior hippocampus was known to be the epileptic focus (Table 1).

\section{GAD-IR puncta densities}

Figures 9 and 10 illustrate typical distributions of GAD-IR puncta (putative GABAergic terminals) on granule cells in FD (Fig. 9) and pyramidal cells of $\mathrm{CA}_{3}$ (Fig. 10). In the human FD, GAD-IR puncta are large (average area, $1.15 \mu \mathrm{m}^{2}$ ) and the most densely packed in appearance because the granule cells $(\mathrm{Gr})$ average only about $10 \mu \mathrm{m}$ in diameter. The puncta (arrowheads) also vary in size (Fig. 9); however, they do not appear shrunken or damaged in this epileptic tissue. GAD-IR puncta appear to surround primarily the clear granule cells in SG; however, the puncta also appear to end on dendrites in the molecular layer (ML) of FD.
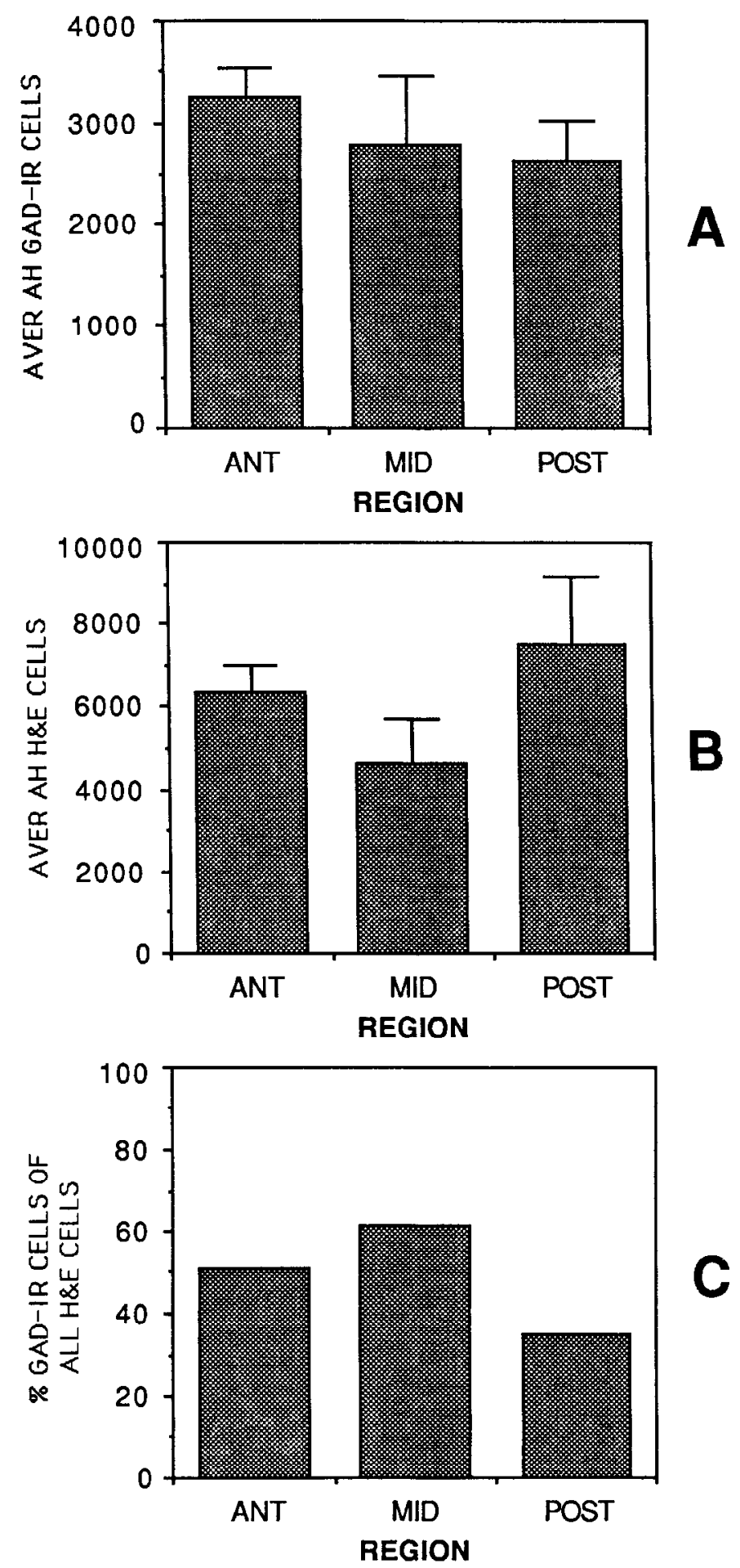

Figure 7. Three histograms comparing the counts of GAD-IR neurons $(A)$, total $\mathrm{H}$ and E-stained neurons $(B)$, and the percentages $(C)$ of $A$ to $B$ counts for the 3 Ammon's horn levels (ANT, $n=18$; MID, $n=3$; POST, $n=6$ ) in 27 hippocampi classified as epileptic on the basis of typical sclerosis, intrahippocampal seizure onsets, and postresection seizure relief. Note that although most seizures in hippocampal epilepsy arise from anterior or middle hippocampus, the GAD-IR neurons are greater, not less ( $A$ : ANT, MID) compared with posterior, where seizures rarely are initiated. By contrast, sclerosis of pyramidal cells is greater in ANT and MID $(B)$ compared with posterior ( $B$ : POST). Hence, there are proportionately more GAD-IR neurons to pyramidal cells in anterior and middle hippocampus ( $C$ : ANT, MID) that has been characterized as being more epileptogenic based on several criteria. 

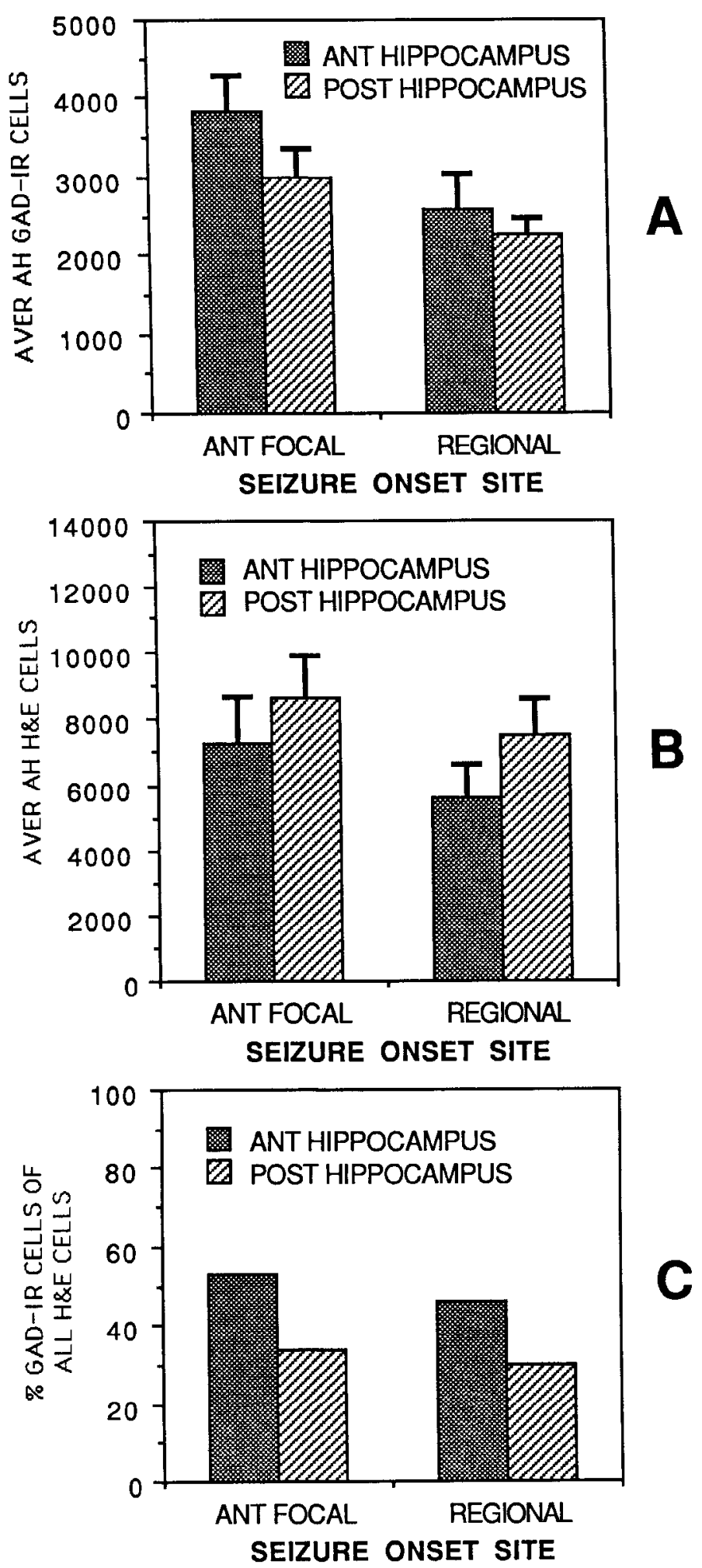

Figure 8. Three histograms comparing GAD-IR neurons $(A)$, total $\mathbf{H}$ and $\mathrm{E}$-stained neurons $(B)$, and the percentages $(C)$ of $A$ to $B$ for anterior versus posterior hippocampus in 11 hippocampi selected on seizure onset site criterion along with the other criteria for epileptic hippocampus. Hippocampi $(n=6)$ from the patients having anterior focal onsets were compared with the hippocampi $(n=5)$ of patients with regional onsets. Both anterior and posterior sections were cut and analyzed from these 11 patients without knowledge of the site(s) of seizure onset. Despite the fact that with anterior focal seizure onsets there are fewer $\mathrm{H}$ and $\mathrm{E}$ ncurons $(B)$, there are actually more GAD-IR neurons $(A)$ in anterior hippocampus, which is the seizure site, than in posterior hip-
The GAD-IR puncta (arrowheads) surrounding remnant pyramidal cells $(\mathrm{P})$ of epileptic $\mathrm{CA}_{3}$ are large (average, $1.0 \mu \mathrm{m}^{2}$ ), well-stained, and do not appear damaged despite the loss of over $75 \%$ of pyramids in this $\mathrm{CA}_{3}$ region (Fig. 10). The puncta densities are greatest on the soma, as reported for rat and monkey (Babb et al., 1988a); however, puncta can also be seen clearly outlining the proximal apical dendrites. Quantitative studies of these GAD-IR puncta using electron microscopy will be presented in another paper.

Figure 11 shows estimated GAD-IR puncta densities in human epileptic and normal monkey hippocampal formations. The puncta densities were computer-imaged in the principal cell strata for each cytologic region in order to determine if there were fewer GABAergic terminals in epileptic tissue. There was no significant difference in any region compared with normal monkey. Furthermore, the GAD-IR puncta densities from these 7 human epileptic hippocampi were calculated from the anterior epileptogenic region, further indicating that GABAergic innervation is relatively normal in sclerotic and epileptic hippocampus.

\section{Discussion}

The present study was designed to test directly whether human epileptic hippocampus contains fewer GABAergic neurons, which might thereby provide less recurrent inhibition whenever principal cells fire. It is now known that in the mammalian hippocampus, interneurons provide recurrent short-latency, longduration inhibition of principal cell firing in rat (Alger and Nicoll, 1982), guinea pig (Knowles and Schwartzkroin, 1981; Lacaille et al., 1987), cat (Spencer and Kandel, 1961; Finch and Babb, 1977), and man (Isokawa-Akesson et al., 1989), which is most likely GABAergic. In order to label these GABAergic interneurons and study them both qualitatively and quantitatively, we have used GAD-ICC. Because brain GAD is known to be the rate-limiting synthetic enzyme for GABA (Roberts et al., 1976), specific antisera for GAD have becn uscd to localize GABA neurons and terminals (Wood et al., 1976; Mugnaini and Oertel, 1985). The anatomy of these GAD-labeled neurons are distributed similarly to interneurons labeled for GABA in the hippocampus (Anderson et al., 1986; Gamrani et al., 1986). In a previous study (Babb et al., 1988a), we demonstrated similar distributions of GAD-IR neurons in hippocampus for rat and monkey, and these distributions coincide well with sites of GABAergic inhibition (Curtis et al., 1970; Andersen et al., 1982), with the GABA-degrading enzyme GABA-T (Storm-Mathisen, 1972) and a high-affinity GABA receptor agonist muscimol (Chan-Palay, 1978). Hence, we have concluded that the use of GAD-ICC provides a valid method for estimating the distribution of GABAergic neurons and terminals in human epileptic hippocampus.

The most important comparison in this study is documented in Figure 8. In 11 patients with exclusively intrahippocampal seizure onsets, typical hippocampal sclerosis and postoperative seizure relief, we processed the anterior and posterior hippocampus of each patient simultaneously in order to contrast GABA neuron densities at the site of only focal anterior $(n=6)$ seizures

pocampus. For regional seizure onsets, the anterior to posterior distributions of GAD-IR neurons are similar. There is no statistically significant difference for any cell count comparison. 


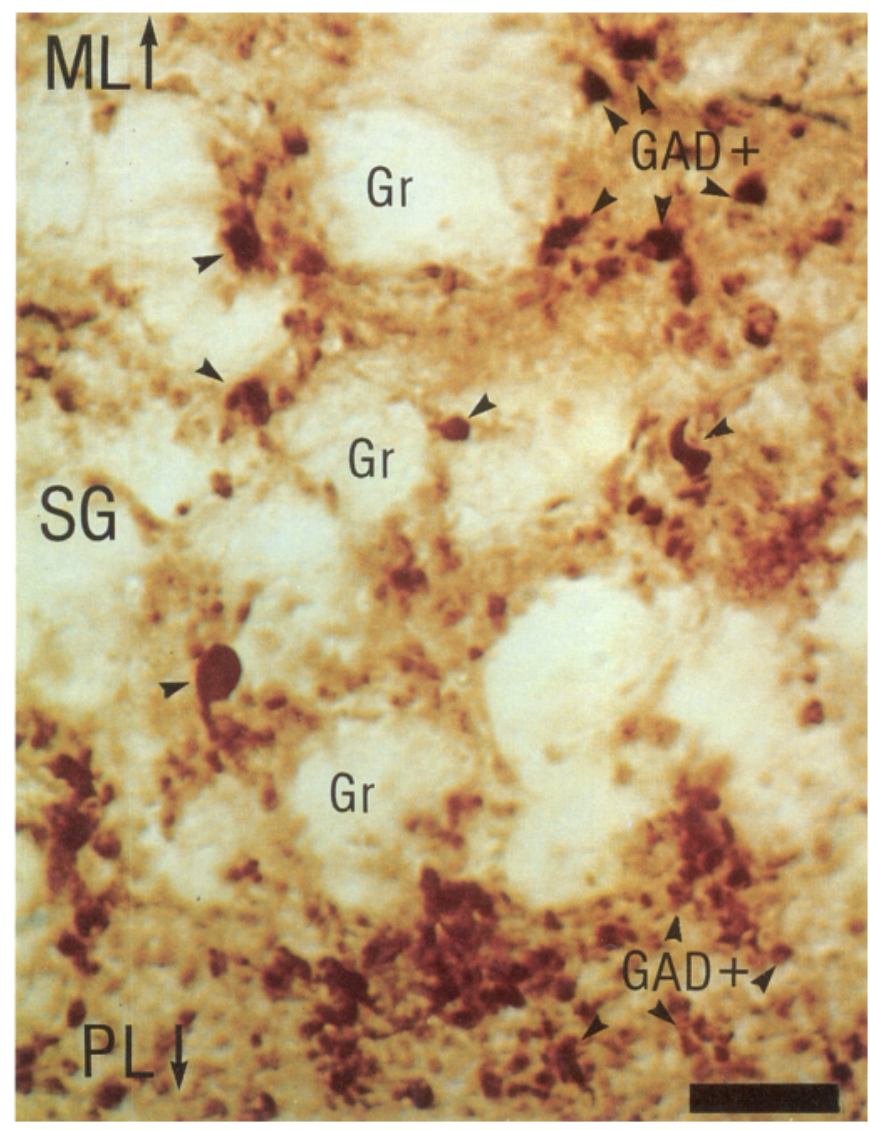

Figure 9. Color photomicrograph of GAD-IR puncta (arrowheads) surrounding granule cells $(\mathrm{Gr})$, which appear as clear circles in epileptic stratum granulosum $(S G)$. Arrows point to directions of molecular layer $(M L)$ and polymorph layer $(P L)$. Scale bar, $10 \mu \mathrm{m}$.

versus nonfocal regional $(n=5)$ onset seizures. Similar controlled comparison done on principal cells in this study and previously (Babb et al., 1984b) demonstrated that the greatest damage was at the site of anterior focal seizure onsets. However, in the anterior hippocampus, GABA densities were actually greater than in posterior hippocampus, even though all focal seizures started anteriorly (none posteriorly). Hence, we can conclude that where the seizures originated, GABA neurons were not reduced statistically but, rather, were numerically greater than in the hippocampus $2 \mathrm{~cm}$ posterior. Figure $8 A$ also shows that for regional onset seizures the GABA densities are not significantly different between anterior and posterior hippocampus. The findings in Figure 8 are the most significant because they do not require comparison across species nor a large sample size to overcome the staining variability inherent in GAD-ICC. Rather, the GABA neuron counts can be directly correlated with the site of seizure onsets. This method has demonstrated that in either focal or regional human hippocampal epilepsy there is no selective or significant loss of GABA neurons. Rather, GABA neurons are resistant to the pathogenic processes that cause hippocampal sclerosis and epilepsy.

Further support for the above conclusion is based on another comparison between anterior, middle, and posterior GABA neurons in human hippocampi. In general, seizures originate from anterior and/or middle hippocampus and not from posterior hippocampus (see, for example, Babb et al., 1984b). However, in 27 patients with the joint "epileptic" criteria of intra-

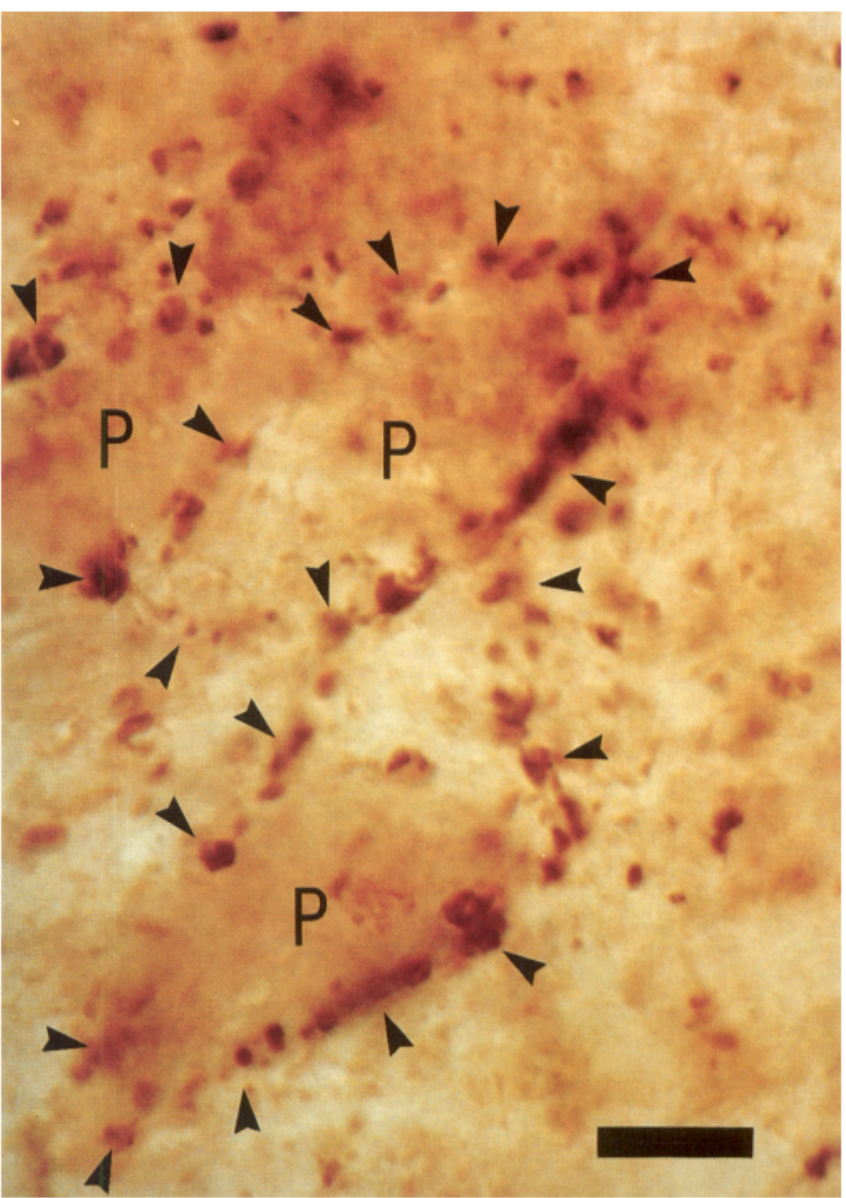

Figure 10. Color photomicrograph of GAD-IR puncta (arrowheads) surrounding remnant pyramidal cells $(P)$ in epileptic $\mathrm{CA}_{3}$. Scale bar, 10 $\mu \mathrm{m}$.

hippocampal seizures, hippocampal sclerosis, and postoperative seizure relief, the GABA neuron densities were actually higher in the more epileptogenic anterior and/or middle hippocampus (see Fig. 7A). Although numerically higher, the anterior/middle GABA densities were not significantly higher statistically. This indicates that the GABA neuron densities per se are not necessarily related to either hippocampal sclerosis (see Fig. $7 B$ ) or epileptogenicity (see Fig. $8 B$ ).

In order to further evaluate whether there are differences in GABA neurons or terminals in various subfields and strata of human epileptic hippocampus, cell and puncta counts were compared with homologous sites in the normal monkey hippocampus. There was no evidence of a selective or significant loss of GABAergic neurons or puncta in any hippocampal region, despite significant principal (non-GAD) cell losses in FD and $\mathrm{CA}$ fields. Compared with normal monkeys, the average loss of GABA neurons in 33 human epileptic hippocampi in various regions was $0-30 \%$ (see Fig. 3); however, that $30 \%$ loss in $\mathrm{CA}_{3}$ was not statistically significant. Hence, focal human hippocampal epilepsy probably cannot be accounted for by a decrease in GABA neurons or terminals. As mentioned in Materials and Methods, evidence from the undamaged human subiculum and normal rat suggests that cross-species comparisons for GABA neuron densities are probably valid enough that our failure to find significant GABA losses in human epileptic hippocampus is accurate, especially with the large sample size $(n$ 


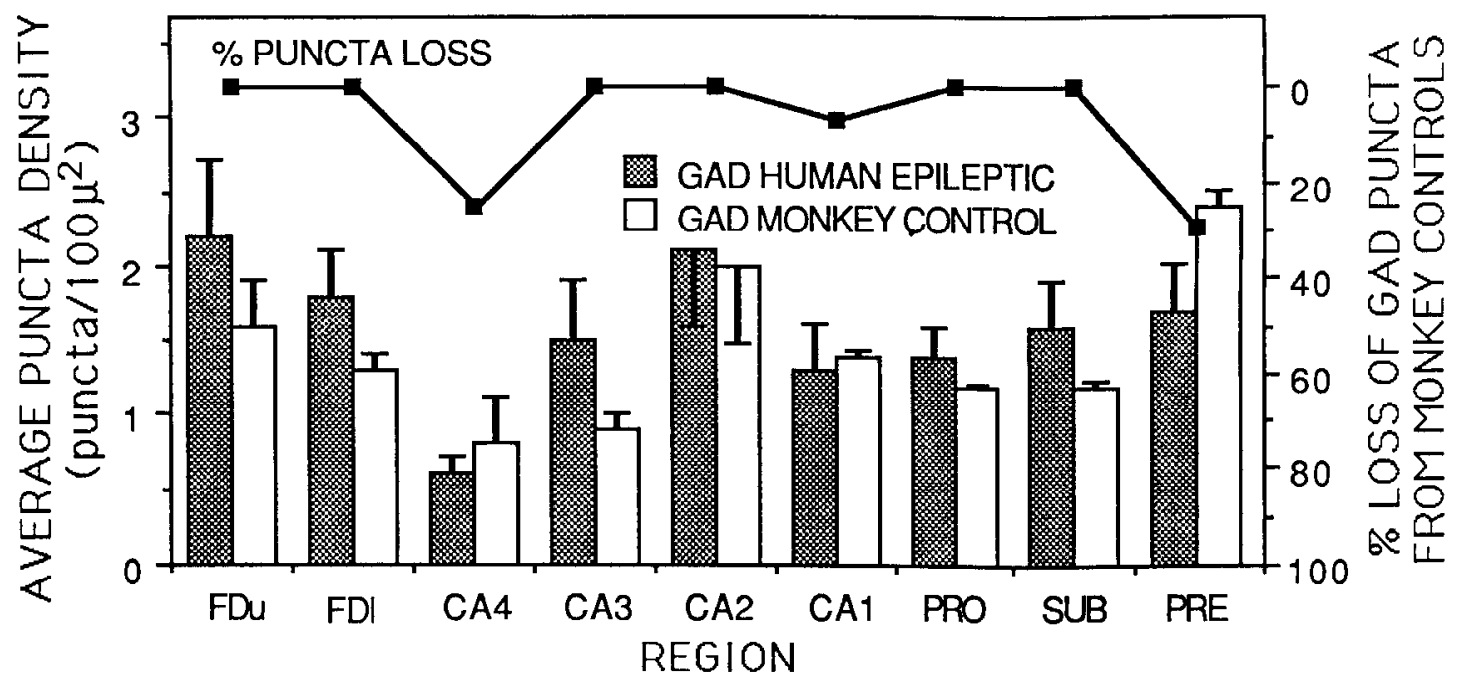

Figure 11. Histogram plot of computer-detected average GAD-IR puncta densities (left ordinate) for all fields in anterior human epileptic hippocampi $(n-7)$. The right ordinate represents the percentage of puncta loss from puncta densitics in monkey $(n-2)$. There is no statistically significant difference between epileptic and monkey for any region of hippocampus. Note that these puncta densities are underestimates of true puncta densities on typical cell membranes because not all cell membranes in the $30-\mu \mathrm{m}$-thick section were imaged in the area calculated. However, the relative puncta densities are valid for comparing different cytologic fields in epileptic and control.

$=33$ ), which would detect even small differences between man and monkey.

Finally, Table 1 shows that only 2 of the 6 patients with anterior focal seizures had fewer averaged GABA neurons in anterior hippocampus, and these reductions ( 8 and $11 \%$ ) were not statistically significant in either case. By contrast, 2 others had anterior GABA densities about twice as numerous as posterior hippocampus. Hence, even on a single-case basis, there were no instances of a relation between significantly fewer GABA neurons and focal hippocampal epilepsy, which may have been masked by group statistics. For example, as detailed in the introduction, Lloyd et al. $(1981,1984)$ reported that $46 \%$ of resected "epileptic" tissue had decreases in GAD activity. Obviously, the other $54 \%$ did not support the hypothesis of decreased GAD activity for GABA dysfunction; hence Lloyd has concluded "Taking the mean from all patients would hide important changes occurring in individual cases. It is evident that there is a subgroup of patients with a deficit in these biochemical markers for GABA transmission (Lloyd et al., 1981, p. 334)." We have been unable to find in our anatomical studies a single example of a loss of GABA neurons (GAD-IR neurons or puncta) that was equal to or greater than the loss of adjacent principal cells typical of hippocampal sclerosis. This suggests that nonspecific damage, which is typical of chronic epileptic foci, may cause decreases in enzyme activities of several transmitter systems, both inhibitory and excitatory.

\section{Damage and $G A B A$ neurons}

The present study represents analysis of tissue with long-standing damage, and we have not yet found evidence to support ongoing recent damage in human epileptic hippocampus (Babb and Brown, 1987). In cytotoxic models of animal seizures, however, there is an opportunity to test whether the time course of seizures parallels nonspecific damage or loss of GABA neurons preferentially. In the alumina model of monkey focal motor seizures, Ribak et al. (1986) have reported a loss of GAD-positive somata ranging from 24 to $52 \%$ depending on the time elapsed since the alumina injection or the chronicity of the seizures. That is, there was no significant GAD-positive cell loss near the granuloma "preseizure" $(n=1)$ or after 3 days of "acute" seizures $(n=1)$. However, the 2 "chronic" seizure monkeys did have significant GAD cell loss compared with homologous contralateral motor cortex. Despite the fact that the authors did not report if there was coincident loss of nonGAD neurons in the same regions, it is interesting that "acute" seizures occurred for $3 \mathrm{~d}$ in the absence of a statistically significant GAD cell loss.

The rodent ischemia model of hippocampal neuron loss following forebrain artery occlusion has demonstrated both acute and delayed neuronal death (Crockard et al., 1980; Kirino, 1982), which is associated with seizures whose likelihood increased from 7 to $20 \mathrm{~min}$ of ischemia (Levy et al., 1975; Kirino and Sano, 1984). However, putative GABAergic neurons are resistant to such insult even after $20 \mathrm{~min}$ ischemia (Johansen et al., 1983), and GAD activity is not dccrcased in even the most affected $\mathrm{CA}_{1}$ sector (Francis and Pulsinelli, 1982). This suggests that GABA neurons for inhibition are preserved despite severe pyramidal cell loss. This pattern of selective pyramidal cell necrosis in $\mathrm{CA}_{1}$ but spared GABA neurons is similar to our findings in human epileptic $\mathrm{CA}_{1}$.

Several studies have used cobalt implants to produce ongoing damage and seizures occurring several days later. Emson and Joseph (1975) correlated the time course of the cobalt lesion, the "epileptic" spike activity and various enzymes in the frontal cortex focus and connected areas. At 8-10 d, all 3 measures were correlated, i.e., necrosis and fiber degeneration was extensive, EEG spiking was at its highest rate and both "inhibitory" (GAD, GABA) and "excitatory" (glutamate and aspartate) markers were depressed. By $24 \mathrm{~d}$, all EEG spiking and neurochemical markers returned to normal, and the authors concluded that their findings did not "support the simple hypothesis (of) a selective elevation of excitatory amino acids or a selective reduction of inhibitory amino acids" (Emson and Joseph, 1975, p. 107). Ross and Craig (1981) found that at $7 \mathrm{~d}$ after cobalt 
implant cortical seizures peaked, GAD activity was reduced $25 \%$ of glass controls and GABA concentration reduced $47 \%$ of glass. However, the GABA receptor number $\left(B_{\max }\right)$ was doubled (200\%). By $21 \mathrm{~d}$ all seizures, spiking and GABAergic measures were normal compared with glass controls. The authors suggested that at the time of "GABA loss" there is a compensatory GABA receptor "denervation supersensitivity." Hence, with the cobalt model of "acute" seizures and spiking there is damage to several transmitter systems coinciding with the ongoing and permanent necrosis. Such nonspecific damage does not support a role for preferential GABAergic mechanisms in acute cobalt epilepsy.

\section{$G A B A$ neurons and hypersynchrony}

The previously mentioned "denervation supersensitivity" or compensatory increase in GABA receptors near a cobalt lesion (Ross and Craig, 1981) has been demonstrated after kainic acid (KA) damage to rat hippocampus (Franck et al., 1988). These authors reported that for 2-4 weeks, physiological GABA-mediated inhibition was smaller than normal, but the receptor number $\left(B_{\max }\right)$ for the GABA-agonist flunitrazepam was significantly increased in the stratum radiatum of $\mathrm{CA}_{1}$. However, the enhanced $B_{\max }$ was normal at $2-4$ months, when the early GABA inhibition was also normal. At no time after KA treatment was there a loss of GAD-IR neurons, which confirms earlier reports (Köhler, 1984; Davenport and Babb, 1985).

These findings of a KA-related increase in the postsynaptic receptor density during the "hyperexcitable" period (2-4 weeks) raises the question of how normal GABA neurons and more GABA receptors could result in hypcrexcitability. In the present study of human epileptic hippocampus, we found "normal" GABA neurons and normal numbers of puncta throughout stratum granulosum or pyramidale, which again raises the question of how such GABAergic anatomy could coexist with hyperexcitability. One hypothesis is hypersynchrony resulting from a greater than normal percentage of GABA terminals on each pyramidal cell. Recall that despite the significant loss $(>50 \%)$ of principal cells (pyramids and granules) throughout the epileptic hippocampus, the GABA puncta density for each hippocampal region was "normal." This would mean that each principal cell actually had more puncta per soma or dendrite. Figure 11 shows that regardless of the hippocampal region measured (FD, CA, SUB, or PRE), there was no significant loss of GAD-IR puncta compared to normal monkey. It is important to recall that the SUB and PRE had no damage compared with monkeys or normal humans. The GABA terminals were not significantly greater there in epileptics; hence the computerized puncta counts were independent of species. By contrast, within the FD and Ammon's horn in epilepsy there was variable principal cell loss, always exceeding 50\% less than normal. Hence, it appears that GABAergic terminals (GAD-IR puncta) hyperinnervate the remnant principal cells to provide potentially more than normal inhibition for each GABA neuron discharge. Because the principal cell loss differs in different hippocampal regions, this hypothesized GABA terminal hyperinnervation appears to proliferate in direct proportion to the local damage. For example, the average FD granule cell loss for the 7 patients in Figure 11 was $50 \%$ and the overall puncta density was normal; therefore, the puncta density per neuron must be approximately twice normal. In the $\mathrm{CA}_{1}$, the average pyramidal cell loss for the 7 patients was $70 \%$ and overall puncta density normal; therefore, the puncta density per neuron would be approximately 3.3 times normal.

\section{Anatomy of $G A B A$ hyperinnervation}

What is the anatomical evidence to support the concept of GABA terminal hyperinncrvation or sprouting in "epileptic" hippocampus? Using fluorescent immunocytochemistry for GAD, Goldowitz et al. (1982) reported a marked increase in the density of GABA fibers in the outer molecular layer following lesions of the entorhinal cortex of rat. Wagner et al. (1983) challenged the interpretation that there was true GABA fiber sprouting because the shrinkage of the outer molecular layer would result in only an apparent increased density per unit area, and in actuality the number of GABA fibers per se would remain unchanged. While this may be a valid observation, in fact, at the synaptic level GABAergic innervation could nevertheless be increased per unit area of molecular layer dendrite. Hence, these papers might support our anatomic GAD-IR puncta counts in human epileptic hippocampus. That is, despite significant cell loss and some shrinkage of principal cell layers, there were no decreases or increases in GAD puncta; hence, the remaining neurons and dendrites have more GABA terminals than normal.

In a study of GAD-IR sprouting into the inner molecular layer (IML) of FD after KA lesion of the $\mathrm{CA}_{4} / \mathrm{CA}_{3}$ associational path, significantly increased GAD-IR puncta densities were found both ipsi- and contralateral to the $\mathrm{KA}$ injection into $\mathrm{CA}_{3}$ (Davenport and $\mathrm{Babb}, 1985$ ). There was concurrent sprouting of mossy fibers into the IML (Frotscher and Zimmer, 1983; Davenport and Babb, 1985) and no measurable shrinkage between the top of the stratum granulosum and the middle molecular layer (MML). Hence, this study supports the model of proliferation of GABAergic innervation of granule cell dendrites. GAD-IR puncta density was also significantly increased in the stratum radiatum of $\mathrm{CA}_{1}$ bilaterally, which represents the site of the ipsilateral and crossed Schaffer collateral system from $\mathrm{CA}_{3}$ to $\mathrm{CA}_{1}$ (Davenport and Babb, 1985). In this reorganized circuit, local GAD-IR fibers apparently sprouted onto the dendrites of $\mathrm{CA}_{1}$ pyramids denervated by $\mathrm{KA}$ damage to $\mathrm{CA}_{3}$. Finally, at 1 month after $\mathrm{KA}$ damage to $\mathrm{CA}_{3}$, and at the time of presumed GAD-IR sprouting in FD, Feldblum et al (1988) have demonstrated increased messenger RNA specific for GAD in hilar neurons presumed to provide GABAergic innervation to FD. The increased levels of GAD messenger RNA presumably would be needed to support the turnover of GAD in the more numerous sprouted GABAergic tcrminals. The above reports support the hypothesis that in human and experimental epileptic hippocampus there are increased GABAergic terminals in either of 2 ways: (1) by simple hyperinnervation where the same number of fibers innervate fewer neurons in a region and terminate more densely on each neuron or (2) by actual sprouting of new fibers to provide more GABAergic terminals on the same number of neurons and/or dendrites. Either of these anatomical rearrangements may occur in damaged hippocampus; however, it is not known how such increased "inhibitory" synapses might promote hyperexcitability.

\section{Physiology of GABA hyperinnervation}

There are no microelectrode studies yet from neurons with experimentally induced and anatomically verified GABA hyperinnervation, such as the apparent GABA terminal sprouting reported above (e.g., Davenport and Babb, 1985). Nevertheless, there are several studies using both intra- and extracellular re- 
cordings from neurons long after KA treatment. These studies all show either a "partial recovery" from earlier hyperexcitability (Franck et al., 1988) or a dramatic hyperexcitability from stimulation (Tauck and Nadler, 1985; Feldblum and Ackermann, 1987). There is no evidence of enhanced inhibition either within 2 weeks (Ashwood et al., 1986) or 2 months (Franck et al., 1988). If this "epileptic" GABA hyperinnervation leads to hyperexcitability and seizure onsets, what synaptic mechanisms could account for it?

One hypothesis is that the GABA "hyperinnervation" is merely compensatory to offset concurrent sprouting of recurrent excitation on the same cells. This would require that the GABA hyperinnervation is weaker than the excitatory hyperinnervation; hence seizure sensitivity will still occur despite greater net inhibition. There is excellent anatomical evidence for recurrent excitatory sprouting in experimental seizure models (Davenport and Babb, 1985; Tauck and Nadler, 1985) and in our human epileptic tissue (Babb et al., 1988b). Such an "imbalance" favoring recurrent excitation in synaptic reorganizations is the simplest explanation for why such tissue is hyperexcitable.

A second hypothesis is that the GABA hyperinnervation contributes to synchronizing the membrane potentials of groups of cells, thereby increasing the numbers of cells firing with the next suprathreshold excitatory input. In other words, because each GABA neuron would innervate and inhibit more cells than normal, when the inhibitory period ended more cells would be at firing threshold simultaneously when the excitatory inputs arrived. Hence, even for a given "normal" excitatory input, more neurons would fire synchronously. With sprouting or hyperinnervation by recurrent excitation, the probability of synchronous discharges of large numbers of neurons would be even greater. We favor this second hypothesis because we have evidence from microelectrode recordings in vivo in human hippocampal epilepsy that there is (1) synchronous firing between neurons in verified epileptic hippocampus (Isokawa-Akesson et al., 1989), (2) prolonged inhibition of neurons prior to focal seizure onset (Babb et al., 1987), and (3) longer feedback inhibition in "epileptic" hippocampal neurons after single stimulation or after paired-pulse tests (Isokawa-Akesson et al., 1989). Finally, in vitro recordings from human "epileptic" neocortex have exhibited large synchronous potentials that were thought to depend on inhibitory interneurons which fired during these potentials. These rhythmic potentials probably were GABAergic because they were blocked by bicuculline and had a reversal potential similar to hippocampal IPSPs, at approximately -60 $\mathrm{mV}$. They could be recorded simultaneously in pairs of neurons separated by $0.5-1.0 \mathrm{~mm}$, which indicates that GABA-mediated IPSPs may synchronize cells in epileptic cortex (Schwartzkroin and Haglund, 1986). We believe that since GABA-mediated inhibition is so divergent in normal hippocampus (Spencer and Kandel, 1961; Finch and Babb, 1977) and would be even more divergent and effective in hyperinnervated epileptic hippocampus, the human spontaneous seizure susceptibility may be a consequence of enhanced synaptic synchrony from both GABA (present study) and excitatory (Babb et al., 1988b) synaptic reorganizations.

\section{References}

Abercrombie, M. (1946) Estimation of nuclear population from microtome sections. Anat. Rec. 94: 239-247.

Alger, B. E., and R. A. Nicoll (1982) Feed-forward dendritic inhibition in rat hippocampal pyramidal cells studied in vitro. J. Physiol. (Lond.) 328: 105-123.

Andersen, P., B. Bie, and T. Ganes (1982) Distribution of GABA sensitive areas on hippocampal pyramidal cells. Exp. Brain. Res. 45: 357-363.

Anderson, K. J., B. E. Maley, and S. W. Scheff (1986) Immunocytochemical localization of $\gamma$-aminobutyric acid in the rat hippocampal formation. Neurosci. Lett. 69: 7-12.

Ashwood, T. J., B. Lancaster, and H. V. Wheal (1986) Intracellular electrophysiology of $\mathrm{CA}_{1}$ pyramidal neurones in slices of the kainic acid lesioned hippocampus of the rat. Exp. Brain Res. 62: 189-198.

Babb, T. L., and W. J. Brown (1987) Pathological findings in epilepsy. In Surgical Treatment of the Epilepsies, J. Engel, Jr., ed., pp. 511540, Raven, New York.

Babb, T. L., W. J. Brown, J. Pretorius, C. J. Davenport, J. P. Lieb, and P. H. Crandall (1984a) Temporal lobe volumetric cell densities in temporal lobe epilepsy. Epilepsia 25: 729-740.

Babb, T. L., J. P. Lieb, W. J. Brown, J. Pretorius, and P. H. Crandall (1984b) Distribution of pyramidal cell density and hyperexcitability in the epileptic human hippocampal formation. Epilepsia 25: 721728 .

Babb, T. L., C. L. Wilson, and M. Isokawa-Akesson (1987) Firing patterns of human limbic neurons during stereoencephalography (SEEG) and clinical temporal lobe seizures. Electroencephalogr. Clin. Neurophysiol. 66: 467-482.

Babb, T. L., J. K. Pretorius, W. R. Kupfer, and W. J. Brown (1988a) Distribution of glutamate decarboxylase immunoreactive neurons and synapses in rat and monkey hippocampus: Light and electron microscopy. J. Comp. Neurol., 278: 121-138.

Babb, T. L., W. R. Kupfer, and J. K. Pretorius (1988b) Synaptic reorganization of mossy fibers into inner molecular layer in human epileptic fascia dentata. Soc. Neurosci. Abstr. 14: 881 .

Burnham, W. M., P. A. Hwang, H. J. Hoffman, L. E. Becker, E. G. Murphy, and S. J. Kish (1987) Benzodiazepine receptor binding in human epileptogenic cortical tissue. In Fundamental Mechanisms of Human Brain, J. Engel et al., eds., pp. 227-235, Raven, New York.

Chan-Palay, V. (1978) Quantitative visualization of $\gamma$-aminobutyric acid receptors in hippocampus and area dentata demonstrated by $\left[{ }^{3} \mathrm{H}\right] \mathrm{muscimol}$ autoradiography. Proc. Natl. Acad. Sci. USA 75: 25162520 .

Crandall, P. H. (1987) Cortical resections. In Surgical Treatment of the Epilepsies. J. Engel, Jr., ed., pp. 377-404, Raven, New York.

Crockard, A., F. Iannotti, A. T. Hunstock, R. D. Smith, R. J. Harris, and L. Symon (1980) Cerebral blood flow and edema following carotid occlusion in the gerbil. Stroke 11: 494-498.

Curtis, D. R., D. Felix, and H. McLennan (1970) GABA and hippocampal inhibition. Br. J. Pharmacol. 40: 881-883.

Davenport, C. J., and T. L. Babb (1985) GAD+ neurons for GABA mediated inhibition in kainate-hippocampal epilepsy. Soc. Neurosci. Abstr. 11: 284.

Davenport, C. J., and T. L. Babb (1986) Kainate induced sprouting of inhibitory (GAD) interneurons and mossy fiber recurrent collaterals in the ipsi and contralateral hippocampus. Soc. Neurosci. Abstr. 12: 343.

Emson, P. C., and M. H. Joseph (1975) Neurochemical and morphological changes during the development of cobalt-induced epilepsy in the rat. Brain Res. 93: 91-110.

Engel, J. E., Jr., P. H. Crandall, and H. R. Rausch (1983) The partial epilepsies. In The Clinical Neurosciences, Vol. 2, R. N. Rosenberg, R. G. Grossman, S. Schachet, E. R. Heinz, and W. D. Willis, eds., pp. 1349-1380, Churchill Livingstone, New York.

Feldblum, S., and R. F. Ackermann (1987) Increased susceptibility to hippocampal and amygdala kindling following intrahippocampal kainic acid. Exp. Neurol. 97: 255-269.

Feldblum, S., R. F. Ackermann, and A. J. Tobin (1988) Kainate injection increases GAD mRNA levels in hilar neurons of the rat hippocampus. Soc. Neurosci. Abstr. 14: 881 .

Finch, D. M., and T. L. Babb (1977) Response decrement in a hippocampal basket cell. Brain Res. 130: 354-359.

Francis, A., and W. Pulsinelli (1982) The response of GABAergic and cholinergic neurons to transient cerebral ischemia. Brain Res. 243. 271-278.

Franck, J. E., D. D. Kunkel, D. G. Baskin, and P. A. Schwartzkroin (1988) Inhibition in kainate-lesioned hyperexcitable hippocampi: Physiologic, autoradiographic and immunocytochemical observations. J. Neurosci. 8: 1991-2002.

Frotscher, M., and J. Zimmer (1983) Lesion-induced mossy fibers to 
the molecular layer of the rat fascia dentata: Identification of postsynaptic granule cells by the Golgi-EM technique. J. Comp. Neurol. 215: 299-311.

Gamrani, H., B. Onteniente, P. Seguela, M. Geffard, and A. Calas (1986) Gamma-aminobutyric acid-immunoreactivity in the rat hippocampus. A light and electron microscopic study with anti-GABA antibodies. Brain Res. 364: 30-38.

Goldowitz, D., S. R. Vincent, J.-Y. Wu, and T. Hökfelt (1982) Immunohistochemical demonstration of plasticity in GABA neurons of the adult rat dentate gyrus. Brain Res. 238: 413-420.

Isokawa-Akesson, M., C. L. Wilson, and T. L. Babb (1989) Inhibition in synchronously firing human hippocampal neurons. Epilepsy Res. (in press).

Jasper, H. H. (1958) The 10-20 electrode system of the International Federation. Electroencephalogr. Clin. Neurophysiol. 10: 371-375.

Johansen, F. F., M. B. Jorgensen, and N. H. Diemer (1983) Resistance of hippocampal $\mathrm{CA}_{1}$ interneurons to $20 \mathrm{~min}$ of transient cerebral ischemia in the rat. Acta Neuropathol. (Berl.) 61: 135-140.

Kirino, T. (1982) Delayed neuronal death in the gerbil hippocampus following ischemia. Brain Res. 239: 57-69.

Kirino, T., and K. Sano (1984) Selective vulnerability in the gerbil hippocampus following transient ischemia. Acta Neuropathol. (Berl.) 62: 201-208.

Knowles, W. D., and P. A. Schwartzkroin (1981) Local circuit synaptic interactions in hippocampal brain slices. J. Neurosci. 1: 318-322.

Köhler, C. (1984) Neuronal degeneration after intracerebral injections of excitotoxins. A histological analysis of kainic acid, ibotenic acid and quinolinic acid lesions in the rat brain. In Excitotoxins, WennerGren International Symposium, Vol. 39, K. Fuxe, P. Roberts, and R. Schwarcz, eds., pp. 99-111, Plenum, New York.

Lacaille, J.-C., A. L. Mueller, D. D. Kunkel, and P. A. Schwartzkroin (1987) Local circuit interactions between oriens/alveus interneurons and CAl pyramidal cells in hippocampal slices: Electrophysiology and morphology. J. Neurosci. 7: 1979-1993.

Levy, D. E., J. B. Brierley, and F. Plum (1975) Ischaemic brain damage in the gerbil in the absence of "no-reflow." J. Neurol. Neurosurg. Psychiatry 38: 1197-1205.

Lloyd, K. G., C. Munari, L. Bossi, C. Stoeffels, J. Talairach, and P. L. Morselli (1981) Biochemical evidence for the alterations of GABAmediated synaptic transmission in pathological brain tissue (stereo EEG or morphological definition) from epileptic patients. In Neurotransmitters, Seizures, and Epilepsy, P. L. Morselli et al., eds., pp. 325-338, Raven, New York.

Lloyd, K. G., L. Bossi, and P. L. Morselli (1984) GABA hypothesis of human epilepsy: Neurochemical evidence from surgically resected identified foci. In Neurotransmitters, Seizures, and Epilepsy II, R. G. Fariello et al., eds., pp. 285-293, Raven, New York.

Lloyd, K. G., L. Bossi, P. L. Morselli, M. Rougier, P. Loiseau, and C. Munari (1985) Biochemical evidence for dysfunction of GABA neurons in human epilepsy. In L.E.R.S., Vol. 3, G. Bartholini et al., eds., pp. 43-52, Raven, New York.

Lloyd, K. G., L. Bossi, P. L. Morselli, C. Munari, A. Rougier, and H. Loiseau (1986) Studies on GABA synaptic function in the epileptic focus. In Intractable Epilepsy, D. Schmidt and P. L. Morselli, eds., pp. 75-85, Raven, New York.

Mouritzen-Dam, A. (1980) Epilepsy and neuron loss in the hippocampus. Epilepsia 21: 617-629.

Mugnaini, E., and W. H. Oertel (1985) An atlas of the distribution of GABAergic neurons and terminals in the rat CNS as revealed by GAD immunocytochemistry. In Handbook of Chemical Neuroanat- omy, Vol. 4: GABA and Neuropeptides in the CNS, Part 1, A. Björklund and T. Hökfelt, eds., pp. 436-608, Elsevier, New York.

Oertel, W. H., D. E. Schmechel, M. L. Tappaz, and I. J. Kopin (1981) Production of specific antiserum to rat brain glutamic acid decarboxylase by injection of an antigen-antibody complex. Neuroscience 6: 2689-2700.

Ribak, C. E., A. B. Harris, J. E. Vaughn, and E. Roberts (1979) Inhibitory, GABAergic nerve terminals decrease at sites of focal epilepsy. Science 205: 211-214.

Ribak, C. E., A. B. Harris, J. E. Vaughn, and E. Roberts (1981) Immunocytochemical changes in cortical GABA neurons in a monkey model of epilepsy. In Neurotransmitters, Seizures, and Epilepsy, P. L. Morselli et al., eds., pp. 11-21, Raven, New York.

Ribak, C. E., C. A. Hunt, R. A. Bakay, and W. H. Oertel (1986) A decrease in the number of GABAergic somata is associated with the preferential loss of GABAergic terminals at epileptic foci. Brain Res. 363: 78-90.

Roberts, E., T. N. Chase, and D. B. Tower (1976) GABA in Nervous System Function, Raven, New York.

Ross, S. M., and C. R. Craig (1981) $\gamma$-Aminobutyric acid concentration, L-glutamate 1-decarboxylase activity, and properties of the $\gamma$-aminobutyric acid postsynaptic receptor in cobalt epilepsy in the rat. J. Neurosci. 1 : 1388-1396.

Schmidt, D., C. Cornaggia, and W. Löscher (1984) Comparative studies of the GABA system in neurosurgical brain specimens of epileptic and non-epileptic patients. In Neurotransmitters, Seizures, and Epilepsy II, R. G. Fariello et al., eds., pp. 275-283, Raven, New York.

Schwartzkroin, P. A., and M. M. Haglund (1986) Spontaneous rhythmic synchronous activity in epileptic human and normal monkey temporal lobe. Epilepsia 27: 523-533.

Sherwin, A., F. Quesney, S. Gauthier, A. Olivier, Y. Robitaille, P. McQuaid, C. Harvey, and N. van Gelder (1984) Enzyme changes in actively spiking areas of human epileptic cerebral cortex. Neurology 34: 927-933.

Sherwin, A., E. Matthew, M. Blain, and D. Guévremont (1986) Benzodiazepine receptor binding is not altered in human epileptogenic cortical foci. Neurology 36: 1380-1382.

Spencer, W. $\Lambda$., and E. R. Kandel (1961) Hippocampal neuron responses to selective activation of recurrent collaterals of hippocampofugal axons. Exp. Neurol. 4: 149-161.

Storm-Mathisen, J. (1972) Glutamate decarboxylase in the rat hippocampal region after lesions of the afferent fibre systems. Evidence that the enzyme is localized in intrinsic neurones. Brain Res. 40:215235.

Tauck, D. I., and J. V. Nadler (1985) Evidence of functional mossy fiber sprouting in hippocampal formation of kainic acid-treated rats. J. Neurosci. 5: 1016-1022.

van Gelder, N. M. (1981) The detection of cerebral dysfunctions by disturbances in the compartmentalized metabolism of certain amino acids. In Neurotransmitters, Seizures, and Epilepsy, P. L. Morselli et al., eds., pp. 129-140, Raven, New York.

Wagner, G. P., W. H. Oertel, and J. R. Wolff (1983) Entorhinal lesions result in shrinkage of the outer molecular layer of rat dentate gyrus leading subsequently to an apparent increase of glutamate decarboxylase and cytochrome oxidase aclivities. Neurusci. Lelt. 39: 255-260.

Wood, J. G., B. J. McLaughlin, and J. E. Vaughn (1976) Immunocytochemical localization of GAD in electron microscopic preparations of rodent CNS. In GABA in Nervous System Function, E. Roberts, T. N. Chase, and D. B. Tower, eds., pp. 133-148, Raven, New York. 